\title{
A Review of Perovskite Solar Cells
}

\section{B. A. Osman *, T. M. Abdolkader, I. S. Ahmed}

Basic Engineering Sciences Department, Faculty of Engineering, Banha University, Banha, Egypt

*Corresponding author: E-mail: basmaosman86@hotmail.com

Received 31 May 2021

Revised 26 June 2021

Accepted for publication 9 November 2021

Published online 11 November 2021

\section{Abstract}

With the fast progress of solar cells efficiency in the last few years, hybrid organic/inorganic metal halide perovskite solar cells (PSCs) became a center point of research for a lot of solar cell researchers. The perovskite materials show different merits like longer carrier diffusion lengths, wider-tunable bandgap in addition to higher potential of light absorption. The higher efficiency together with the cheaper fabrication methods makes perovskite solar cells comparable with Si-based solar cells. The PSCs efficiency has a remarkable increase from $3.8 \%$ to more than $25.2 \%$. There is a great need for an overall understanding of the function of each of the solar cell components and its impact on cell efficiency and performance. This review starts with the discussion of perovskite structure (electronic and crystal) based on recent research. The working principles and the fabrication methods of PSCs are also introduced. PSCs evaluation is also analyzed and presented with more details regarding modelling approaches and simulation tools.

Keywords: Solar cell; Perovskite solar cell; Perovskite structure; Perovskite materials; Diffusion length; Tunable band gap.

\section{Introduction}

The consumption of global energy has gradually increased [1]. There is a great demand to search for renewable and sustainable energy sources because of fossil fuels' limited abundance. The transformation of sunlight into electricity is considered one of the most hopeful researches to face the growing energy needs for generations in the future without affecting the global climate [1, 2]. Recently, some technologies of emerging photovoltaic (PV) showed a growing concern in low-cost processes, lightness, and flexibility [3, 4]. Solar cell energy is an alternative energy that is considered one of the most significant sources of renewable energy over the years [3]. Perovskite Solar Cells (PSCs) have experienced an unexpected meteoric appearance as a new family of solar cell technologies [5]. Organic-inorganic metal halide PSC is a promising alternative to current PV technologies with the same ability of solution-process and high performance [6]. Another remarkable property, that was discovered 50 years ago, is their ferroelectric behavior. The direct energy band gap $E_{\mathrm{g}}$ of perovskite extends from 1.3 to $2.2 \mathrm{eV}$ and it is responsible for its optical properties that are important for harvesting and converting ultraviolet (UV) and near-infrared (NIR) light into visible light to be used by the active layer of the perovskite as shown in Fig. 1 [7].

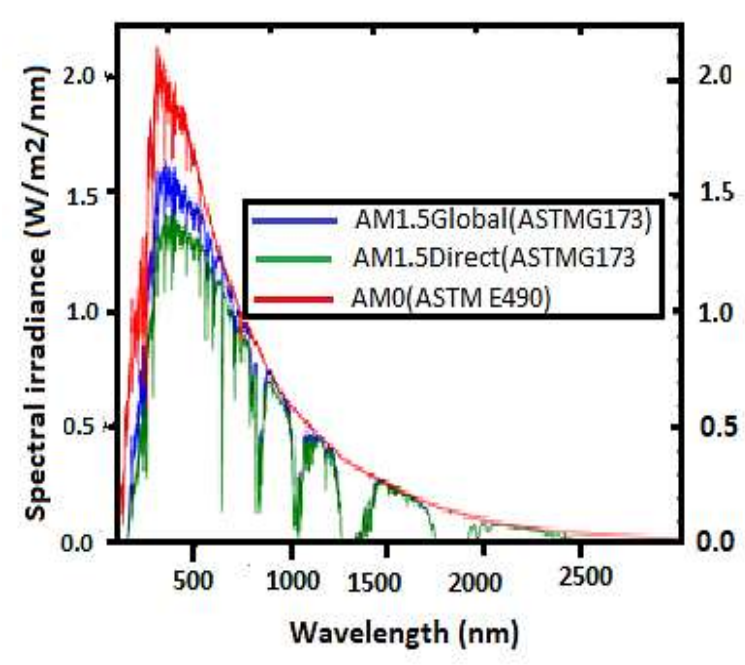

Fig. 1 Standard solar spectral [7]. 
Hybrid organic-inorganic PSCs have had a great interest since 2009 with Power Conversion Efficiency (PCE) which raised exponentially from 3.8\% [8] to $6.5 \%$ in 2011[7] to about $23.3 \%$ in 2016 [7] and reaches $25.2 \%$ by 2021 [9-13] as shown in Fig. 2. Regardless of the PSC high efficiency, there is a lack of reasons for PSC degradation and instability which is an obstacle for commercialization in our life. Therefore, there is a need for more information about the cell for further improvement in performance and stability [14] and must take the minimum recombination and maximum separation of charges considerable for higher performance [15]. Consequently, based on previous studies, this review introduces various PSC structures and the techniques of this new technology, makes a comparison between them to get the points of shortage to be able to optimize this technology and determine the most promising and reliable materials, structures that help to get the best performance in the future work.

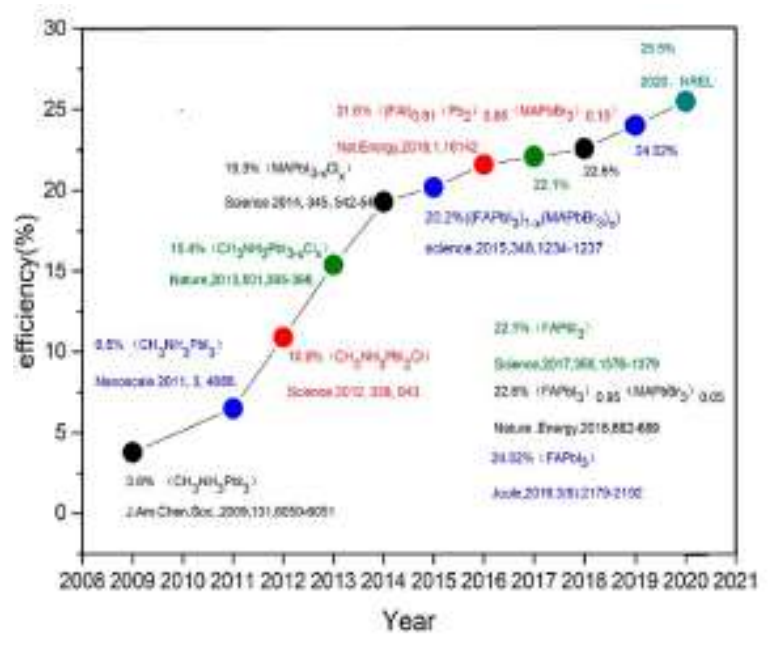

Fig. 2 Recorded Power Conversion Efficiency of the PSC in progressive years [16].

Herein, we review in section 2 the PSC structure (crystal and electronic) and discuss various types of metal halide PSC. Section 3 studies how the PSC is working when exposed to sunlight. Section 3 introduces in detail the different structures of PSC (planar, inverted, and mesoporous) and how to fabricate this cell is reviewed in section 4. Meanwhile, the review of ferroelectric PSC and its fabrication technique is also illustrated. Section 5 tends to provide an overview on the significant progress of various modelling and simulating techniques (COMSOL, AMPS, MULTIPHYSICS, Solar cell Capacitance Simulator, GPVDM, TiberCAD and SILVACO, MATLAB, wxAMPSa) which can make perovskitebased solar cells a market viable.

\section{Perovskite Solar Cells}

\subsection{Crystal and Electronic Structure of}

\section{Perovskite}

Perovskite materials have gained great interest because of their unique thermal, electromagnetic, and optical properties and the cubic lattice-nested octahedral layered structures [8]. There are possible phases of perovskite structure [7]: 1) Orthorhombic structure phase" when $T=160^{\circ}$ K. 2) Tetragonal structure phase " $\beta$ " occurs when $T<330^{\circ}$ K. 3) Cubic structure phase " $\alpha$ ” occurs for $T=330 \mathrm{~K}$ [17].

Perovskite has two major categories of crystal structure: 1) halo-alkanes perovskite, 2) halide perovskite "organic/inorganic" [7] with $\mathrm{ABX}_{3}$ structure [3]. Any material with a crystal structure similar to the mineral $\mathrm{CaTiO}_{3}$ (discovered in 1839) [7] is called perovskite as shown in Fig.3 [18].
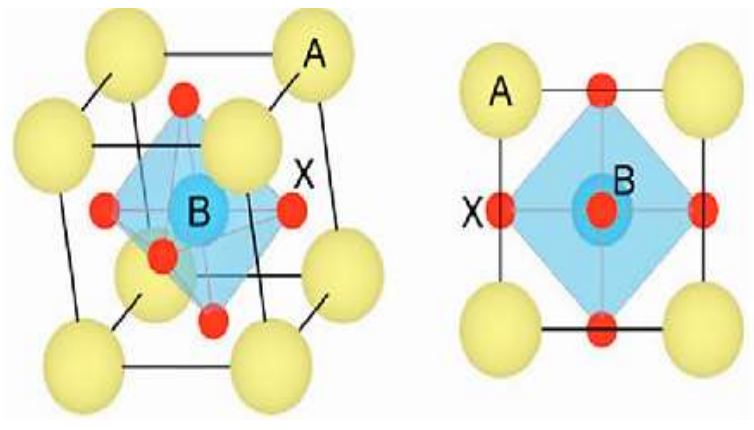

Fig. 3 A general crystal structure of perovskite with the formula ABX3 [19].

In $\mathrm{ABX}_{3}$ formula, $\mathrm{A}$ is a large cation (organic or inorganic) [3, 20,] such as formamidinium $\left(\mathrm{FA}^{+}\right.$, $\mathrm{CH}\left(\mathrm{NH}_{2}\right)_{2}{ }^{+}$) or methylammonium (MA+, $\left.\mathrm{CH}_{3} \mathrm{NH}_{3}{ }^{+}\right)$ and is located at the vertex of the face-centered cubic lattice [7]. Group B is a small inorganic cation $\left(\mathrm{Cu}^{2+}\right.$, $\left.\mathrm{Sn}^{2+}, \mathrm{Pb}^{2+}\right)$ and $\mathrm{X}_{3}$ is an ion that is capable of bonding $\mathrm{A}$ and $\mathrm{B}$ such as $\mathrm{Cl}^{-}, \mathrm{Br}^{-}$and $\mathrm{I}^{-}$as shown in Fig. 4 $[3,14,20,21]$.

In the last few years, Lead Halide Perovskite Solar Cells (LHPSCs) $\left(\mathrm{CH}_{3} \mathrm{NH}_{3} \mathrm{PbX} 3, \mathrm{X}=\mathrm{Cl}, \mathrm{Br}, \mathrm{I}\right)$ have gained great attention because of their simpler processing techniques and lower cost compared with traditional silicon solar cells [22, 23]. Particularly, Lead-Iodine perovskite $\left(\mathrm{CH}_{3} \mathrm{NH}_{3} \mathrm{PbI}_{3}\right)$ with a $1.5 \mathrm{eV}$ direct band gap has been considered as one of the most ideal light absorbers because of its high extinction coefficient, low exciton binding energy, good charge carrier mobility, easy processing ability, and low expense. PCE has been reached over $25 \%$ thus far [9], 
while it is predicted to increase by optimizing the devices and their materials in the future.

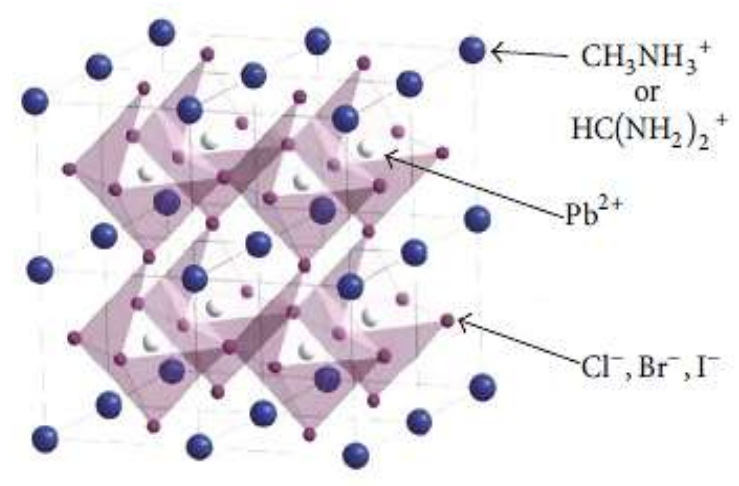

Fig. 4 Cubic lattice of perovskite structure [8].

Chloride/Iodide mixed halide perovskite $\mathrm{MAPbI}_{3}$ ${ }_{\mathrm{x}} \mathrm{Cl}_{\mathrm{x}}$ is utilized in a wide range because of the thermal stability of the $\mathrm{MAPbI}_{3-\mathrm{x}} \mathrm{Cl}_{\mathrm{x}}$ films that is up to $140{ }^{\circ} \mathrm{C}$ and its better carrier diffusion lengths than $\mathrm{MAPbI}_{3}$ (Methyl-ammonium lead iodide) [18]. Despite the worthy progress of the perovskite solar cells, lead toxicity remains the main obstacle to the wide PSCs applications [22, 24]. Consequently, this instability and toxicity of lead PSCs may handicap its commercial production scale and its potential use. These complications of lead demand to search for an alternative candidate ecologic hybrid perovskite material that will achieve the same efficiency [25]. Experimental and theoretical studies show that Tin halide perovskite solar cell $\mathrm{CH}_{3} \mathrm{NH}_{3} \mathrm{SnI}_{3}\left(\mathrm{MASnI}_{3}\right)$ with a narrow bandgap of $1.3 \mathrm{eV}$ can be a possible replacement to LHPSCs because it covers a broader range of the visible light spectrum than LHPSCs. In addition, planar heterostructure of Tin (Sn) PSCs has been developed and achieved 3\% of efficiency with optical bandgap extending from $1.3 \mathrm{eV}$ to $1.4 \mathrm{eV}$. Furthermore, similar to LHPSCs, the bandgap can be tuned from $1.3 \mathrm{eV}$ to $2.15 \mathrm{eV}$ by replacing iodine (I) with bromine $(\mathrm{Br})$ which increases the bandgap. This bandgap tunability provides a good chance to use Tinbased perovskites as a possible substitution for LHPSCs in solar cell applications [15, 19]. The major limitation for the tin-based perovskite performance is the oxidation of tin from $\mathrm{Sn}^{2+}$ to $\mathrm{Sn}^{4+}$ in the air [22, 26, 27]. Extensive research increases the stability of the Snbased devices by developing encapsulation processes. Adding Tin Fluoride $\left(\mathrm{SnF}_{2}\right)$ in the synthesis process decreases the oxidation chance of $\mathrm{Sn}^{2+}$ to $\mathrm{Sn}^{4+}[22,26]$. Germanium $(\mathrm{Ge})$ based perovskite $\left(\mathrm{CH}_{3} \mathrm{NH}_{3} \mathrm{GeX}_{3}\right)$ has the same performance as lead $\mathrm{Pb}$ and $\mathrm{Sn}$ because it belongs to the same subgroup of $\mathrm{Pb}$. In 2013, Stoumpos et al. was the first one to synthesize the lead-free germanium iodide perovskite materials $\mathrm{CH}_{3} \mathrm{NH}_{3} \mathrm{Gel}_{3}$ and discovered highly distorted structure and strong nonlinear optical properties. Consequently, Krishnamoorthy et al. in 2015 synthesized $\mathrm{CH}_{3} \mathrm{NH}_{3} \mathrm{Gel}_{3}$ which had a great potential in PV applications. Recently, Nagane et al. (2018) synthesized a mixed $\mathrm{Ge}-\mathrm{Sn}$-based perovskite material which is suitable for more efficient single-junction SCs [25].

\subsection{Perovskite Solar Cell Structure}

The typical PSC architecture consists of three main layers: a perovskite absorber layer sandwiched between a hole transport layer (HTL) and an electron transport layer (ETL) [25, 28]. These materials are located between two electrodes back contact (BC) and front contact (FC) as shown in Fig.5. Perovskite compound absorbs the SC radiation which generates electron-hole pairs (e-h). The HTL and ETL permit a selective number of charge carriers to flow to their electrodes [1, $25]$.

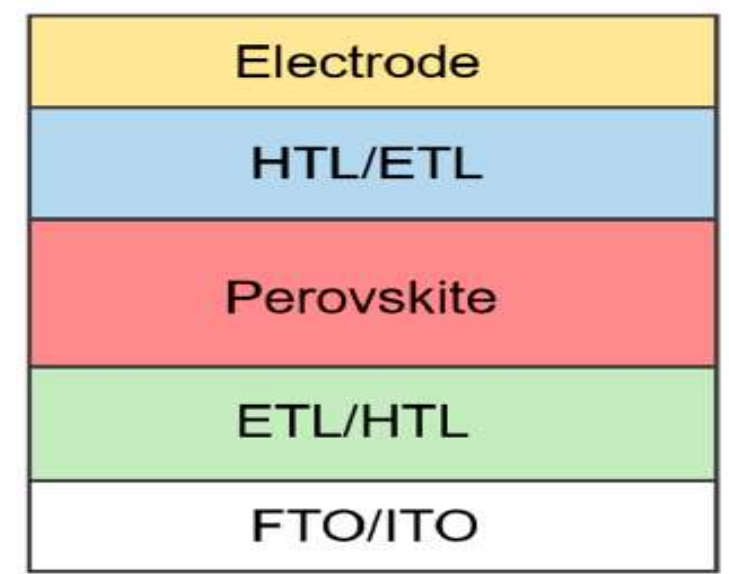

Fig. 5 Structure of PSC [29].

For the Hole Transport Materials (HTM), 2, 2', 7 , 7'-tetrakis [N, N-di(4-methoxyphenyl-amino]- 9,9'spirobifluorene (Spiro-OMeTAD) is considered the benchmark for PSC [30-32] but it is very expensive. Thus, it is very important to find new types of HTMs to get strongly performed PSCs with high reproducibility, low cost, and good stability. There are two categories of HTMs: inorganic materials such as Cuprous thiocyanate Copper (CuSCN), Copper Iodide $(\mathrm{CuI})$, Nickel Oxide (NiO), and cuprous oxide $\left(\mathrm{Cu}_{2} \mathrm{O}\right)$ [33] and organic materials such as Spiro-OMeTAD, Poly(3-hexylthiophene-2,5-diyl) (P3HT) [3,15], Poly(3,4-ethylene dioxythiophene) Polystyrene sulfonate (PEDOT: PSS) and Poly [2,5-bis (3- 
tetradecylthiophen-2-yl thieno [3, 2-b] thiophene (DPBTTT-14) [25]. Besides the absorber, ETL and HTL, there is the BC. Conventionally, Au (Gold) is utilized as the metal back contact. There were many efforts to replace $\mathrm{Au}$ with inexpensive contacts, in HTM-free devices as Ni (Nickel), Pd (Palladium), Pt (Platinum), $\mathrm{Cu}$ (Copper), and Ag (Silver). On the other hand, previous researchers discovered a lot of Electron Transport Materials (ETMs) such as Zinc Oxide $(\mathrm{ZnO})$, Titanium Dioxide $\left(\mathrm{TiO}_{2}\right)$, Cadmium Sulfide (CdS), Zinc Selenide (ZnSe), Zinc Oxy Sulfide (ZnOS) [5, 18], Cerium Oxide (CeOx) [34], [6,6]phenyl C61-butyric acid methyl ester ( $\left.\mathrm{PC}_{61} \mathrm{BM}\right)$ [35] as shown in Fig.6.

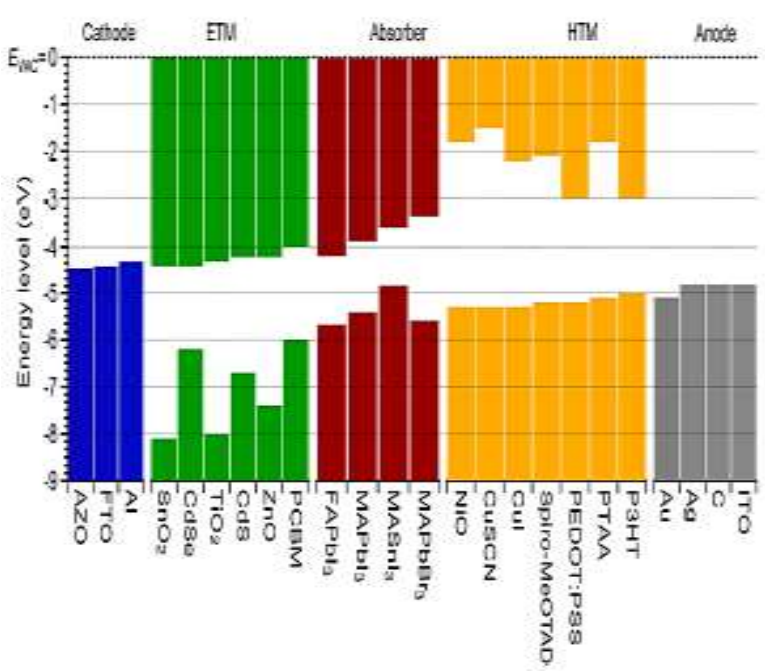

Fig. 6 Diagram showing the energy levels, from left to right, for representative cathode, n-type (ETM), absorber, p-type (HTM), and anode materials [36].
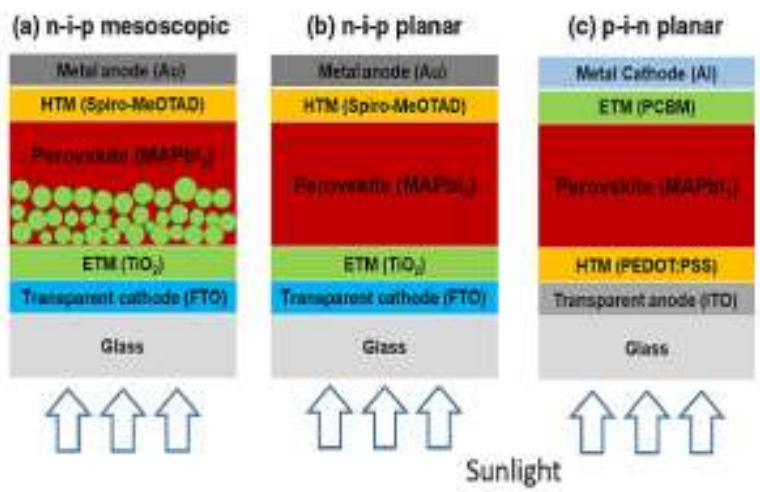

Fig. 7 Schematic diagrams of perovskite solar cells in the (a) n-i-p mesoscopic, (b) n-i-p planar, (c) p-i-n planar) [36].

Recently, three different common structures of PSCs have been developed: mesoporous perovskite solar cell $(n-i-p)$, planar perovskite solar cell $(n-i-p)$, and planar perovskite solar cell $(\mathrm{p}-\mathrm{i}-\mathrm{n})$ [8, 37, and 38] as shown in Fig.7. In the n-i-p structure, light penetrates ETL and the transparent conducting layer lies in front of ETL. The opposite arrangement is the $\mathrm{p}-\mathrm{i}-\mathrm{n}$ structure [1].

\subsubsection{Mesoporous Perovskite Solar Cell (n-i-p)}

Recently, the Mesoporous Perovskite Solar Cells (MPSCs) have gained more attention because of their low-cost materials, easy fabrication method, and high PCE. In MPSC, the compact layer is deposited on a fluorine doped tin oxide layer (FTO), which usually blocks holes and extracts electrons [1]. A typical MPSC involves nanoscale pores in ETL scaffold [39]. First, the absorber layer covers the ETL, makes a compact capping layer, and then penetrates it which forms an intermixed layer. Sequentially, the top electrode and the HTL are deposited above the absorber layer to complete the device [37]. Therefore, the mesoporous layer needs one more step in the fabrication process, which is undesirable for scaling. It is still under discussion that mesoporous layer is indispensable for improving stability or getting higher PCE [37].

It is allowed to adhere the perovskite material to the mesoporous material with increase the receiving light area of the photosensitive material and achieve more efficient PSC as shown in Fig.8 [8]. In addition to the most common mesoporous ETM $\left(\mathrm{TiO}_{2}\right)$, there are other mesoscopic metal oxides: Aluminium Oxide $\left(\mathrm{Al}_{2} \mathrm{O}_{3}\right), \mathrm{ZnO}$, Tin dioxide $\left(\mathrm{SnO}_{2}\right)$ [40], and Zirconium dioxide $\left(\mathrm{ZrO}_{2}\right)$ [19].

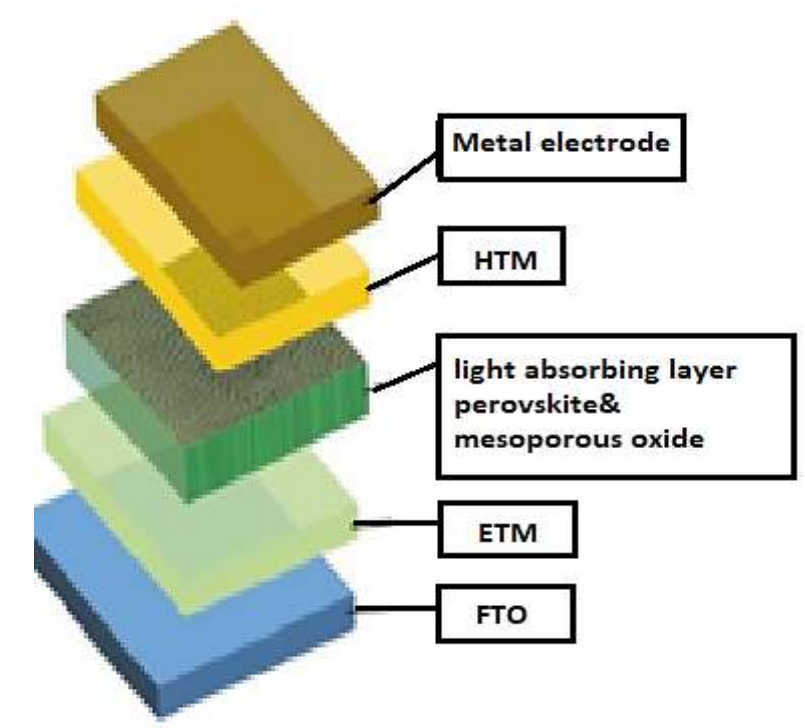

Fig. 8 Schematic diagram of mesoscopic architecture PSCs [8]. 


\subsubsection{Planar Perovskite Solar Cell ( $n-i-p)$}

Planar perovskite solar cells (PPSCs) have been studied on a wide range because of their unique merits such as low-temperature process, low cost, and easy processing [1]. The planar $n-i-p$ structure has a compact ETM layer and it is different from the intermixed layer (perovskite-ETM) in the mesoporous architecture [37]. There are two interfaces (ETL/ perovskite) and (perovskite /HTL). Therefore, the e-h pairs are separated effectively and rapidly by ETL and HTL [1].

\subsubsection{Planar Perovskite Solar Cell ( $p-i-n)$}

PSCs with inverted structure $(\mathrm{p}-\mathrm{i}-\mathrm{n})$ have a great potential for highly performed and flexible PV devices due to their numerous advantages such as easy processing techniques, high stability, and negligible hysteresis [1]. Generally, the planar $\mathrm{p}-\mathrm{i}-\mathrm{n}$ architecture is called an inverted planar structure due to the inversion of the extraction layer of a carrier of the $n-i-$ $\mathrm{p}$ structure. A p-i-n architecture is often built with a planar structure with a compact HTL [37].

Typically, inverted structures use semiconductorsorganic as both ETM layer and HTM layer such as [6, 6]-Phenyl-C61butyric acid methyl ester (PCBM), Indene-C60 bisadduct (ICBA), C60 SAM or polyelectrolyte poly [(9,9-bis(3-(N,N-dimethylamino) propyl)-2,7-fluorene)-alt-2,7-(9,9-dioctylfluorene)]

(PFN). In PPSCs, every layer has an effective influence on the performance of the device. Many strategies were adopted to optimize the inverted PSCs performance such as crystalline regulation of perovskite, design a new perovskite composition, geomorphology control, and modifying the charge carriers' transport layers [1].

\subsection{Ferro-Electric Perovskite Solar Cell}

Most studies of ferroelectric PVs were focused on a restricted group of oxide perovskites and variational combinations of them: Barium Titanate $\mathrm{BaTiO}_{3}$ (BTO), Lithium Niobate $\mathrm{LiNbO}_{3}$ (LNO), Bismuth ferrite $\mathrm{BiFeO}_{3}$ (BFO), and Lead titanium zirconium oxide $\mathrm{Pb}$ (Ti, $\mathrm{Zr}$ ) $\mathrm{O}_{3}$ (PZT) [41]. Hybrid perovskites $\left(\mathrm{MA}-\mathrm{PbI}_{3}\right)$ display ferroelectric properties similar to other perovskites such $\mathrm{BaTiO}_{3}$ and metaloxide perovskites such as $\mathrm{BiFeO}_{3}$ [42]. The materials have ferroelectric nature which is responsible for a lot of effects such as their suitable behavior at the above band gap voltage. This PV effect appears at the ferroelectric domain boundaries by the separation of charges to generate a photocurrent. Ferro electricity has experimentally been observed in hybrid halide perovskite with $(1100 \mathrm{~nm})$ ferroelectric domains which exist in $\mathrm{CH}_{3} \mathrm{NH}_{3} \mathrm{PbI}_{3}$ films [43]. The spontaneous polarization is formed from a cubic toward orthorhombic deformation of $\mathrm{ABO}_{3}$ crystalline structure. Instead of that, at the center of the dipole moment in $\mathrm{MA}-\mathrm{PbI}_{3}$ is the interaction between the $1 e$ charge transfer from the $\mathrm{PbI}_{3}-$ cage to the $\mathrm{N}+$, and the non-Centro-symmetric position of the charge center. In addition, the isolated molecule owns a 2.2 Debye dipole moment [44]. Besides being a low-cost solution that results in high efficiency, the material itself is the most intriguing point [42]. Ferroelectric materials are capable of hosting a permanent electrical polarization that provides control over the distribution of electric fields in interfacial and bulk regions. According to the ferroelectric semiconductor films with ideal contacts, the metallic layers are responsible for screening the polarization charges totally and this leads to no collection of the charge field. Ferroelectric materials layers are located between electrodes and illuminated layers. This exhibits a set of rich phenomena which includes the formation of photo-excited charge carriers. The polarization, which is exhibited by the ferroelectric layer, induces an internal electric field. This electric field helps in the separation of photoexcited carriers and generation effective built-in field at the electrode /ferroelectric interfaces due to Schottky barriers which deplete the ferroelectric layers. The ferroelectric material leads to unique photovoltaic behavior with atomistic asymmetry of the current generation and the bulk PV effect [42].

\section{Working Principle of Perovskite Solar Cell}

The solar cell is considered the main element in a PV array [46]. Solar cells are built by semiconductor materials that convert sunlight into electrical energy by using a PV effect $[46,47]$. It must have the highest possible PCE to make its function satisfactory [45]. It is necessary to understand the basic processes or steps which are undertaken in the SC layers and the function of each component to design highly performed SCs and to understand the PV action [48].

When solar cells are exposed to light, a part of the photons with energy larger than $E_{g}$ is absorbed by the layer of semiconductors. The absorbed photons which have sufficient excitation energy $\left(E>E_{g a p}\right)$ cause the transportation of holes and electrons (holes in the valence band and electrons in the conduction band) in different directions, as shown in Fig.9 [46]. Because of the difference in the binding energy of excitons in perovskites, the excitons can form (free holes and electrons) free carriers to generate current or recombine into excitons [8]. 
The e-h pairs are generated in the field region, and then they are separated under the effect of this field. Consequently, electrons move to the n-side and the holes to the p-side. Some electrons and holes accumulate at the field region boundaries of the $\mathrm{N}$-side and P-side neutralizing part of them, by sequent. The remaining electrons and holes flow in the outer circuit to the load [45]. The free holes and electrons are collected at the same time by HTL, ETL, then by the metal electrode and FTO, by sequent [8]. Not only the electrostatic field can offset parts of the potential energy barrier effects but also cause the P-region to have positive electricity and N-region to have negative electricity.

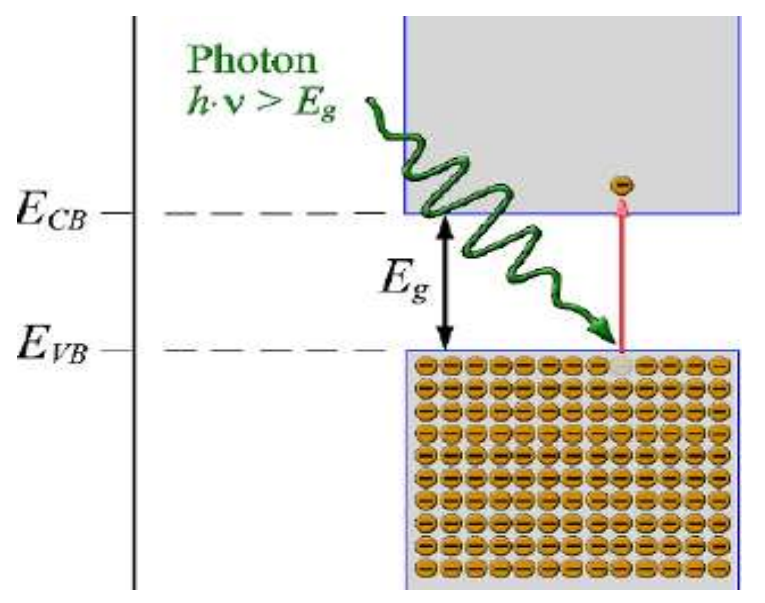

Fig. 9 Photo-generation of an electron-hole pair in a semiconductor [49].

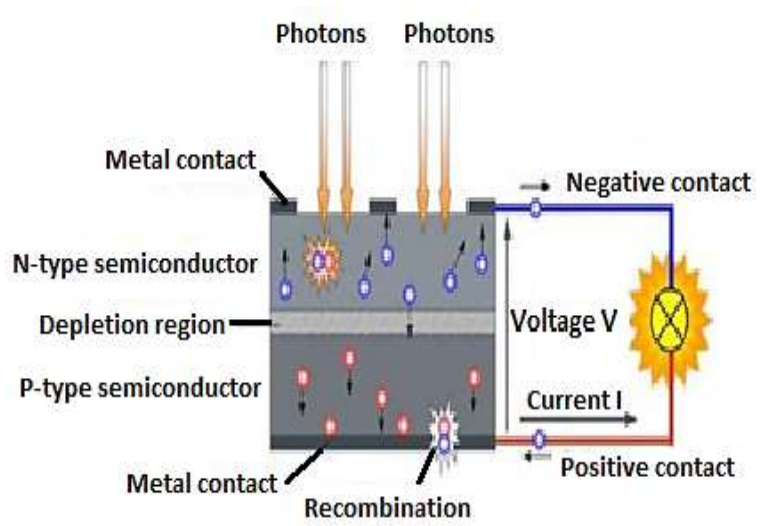

0 Hole=positive charge o Electron=negative charge

Fig. 10 Solar cell working principle [50].

Consequently, the electromotive force is generated between these two regions. Finally, Current flows if a circuit loop is applied [46]. The complete process is shown in Fig.10. It is found that the carrier diffusion distance and lifetime of $\mathrm{CH}_{3} \mathrm{NH}_{3} \mathrm{PbI}_{3}\left(\mathrm{MAPbI}_{3}\right)$ and other perovskites are long due to the lower carrier recombination probabilities and higher carrier mobility. For example, the distance of carrier diffusion for $\mathrm{MAPbI}_{3}$ is at least $100 \mathrm{~nm}$ and longer than $1 \mu \mathrm{m}$ for $\mathrm{MAPbI}_{3-x} \mathrm{Cl}$. The longer lifetime and diffusion distance of carriers are the reasons for the excellent performance of PSCs [8].

\section{Fabrication Techniques}

A typical metal halide PSC with planar (regular) structure (n-i-p) is Glass/TCO/ ETL /Perovskite layer/HTL /Au and with inverted planar structure (p-i$\mathrm{n}$ ) is Glass/ (Transparent Conducting Oxide (TCO)/ HTL /Perovskite layer/ETL /Ag or Al. To form mesoporous structure PSC, there is an additional layer to the planar structure as follows Glass/TCO/c-ETL $/ \mathrm{mp}-\left(\mathrm{TiO}_{2}, \mathrm{SnO}_{2}\right.$, or $\left.\mathrm{Al}_{2} \mathrm{O}_{3}\right) /$ Perovskite layer/HTL /Au. So, the fabrication methods are different from one type to another. Here, we will make a simple review of the fabrication methods of planar (regular, inverted), mesoporous and ferroelectric PSCs from previous studies.

\subsection{Planar Perovskite Solar Cell}

Zhen $\mathrm{Li}$ et al. studied the planar perovskite films deposition through solution processing. At first, lead and organic halides are dissolved in organic solvents like Dimethyl Sulfoxide (DMSO), N, N-Dimethyl Formamide (DMF), and $\gamma$-Butyrol Actone (GBL).

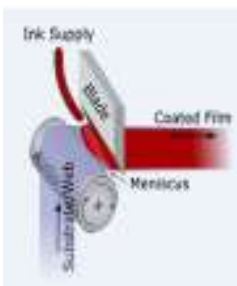

(a) Blade coating

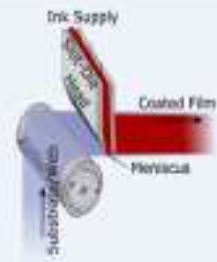

(b) Slot-die coating

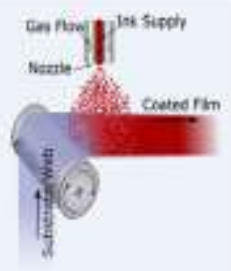

(c) Spray coating
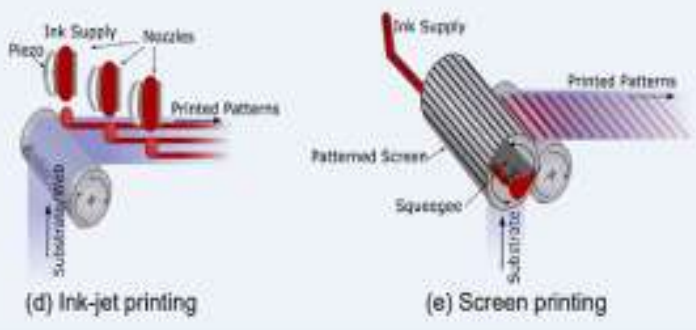

(e) Screan printing

Fig. 11 Common scalable solution deposition methods for the roll-to-roll fabrication of perovskite solar cells. Scalable methods for perovskite deposition include blade coating (panel a), slot-die coating (panel b), spray coating (panel c), inkjet printing (panel d), and screen printing (panel e) [52]. 
These precursor solutions of perovskite can be used in both scalable deposition and spin coating methods. Perovskite scalable deposition methods growth include, but not only, meniscus coating [37], blade coating, slot-die coating, spray coating, inkjet printing [37,51], and electrodeposition as shown in Fig.11 [37]. Longbin Qiu et al. made a simple summary about the updated deposition methods of perovskite layers and examined their suitability for modules and industrial production of PSCs. They developed different technologies for thin film deposition such as spin coating, spray-deposition, optimization for large areas, vapor-based deposition, doctor blading, printing, slotdie coating, soft-cover deposition, and dip coating to synthesize highly performed perovskite films with a large area (structural defects with a low density such as pinholes, decrease surface roughness and uniform good film). They also illustrated the deposition methods of $\mathrm{TiO}_{2}$ "The most popular used ETL material "as follows sputtering coating, screen printing, and spray coating and Spiro-MeOTAD “The most common HTL material "by vacuum deposition [53].

To fabricate $\mathrm{FASnI}_{3}$-based PSCs with the inverted structure PSCs ITO/ $\mathrm{NiO}_{\mathrm{x}} / \mathrm{FASnI}_{3} / \mathrm{PCBM} / \mathrm{Ag}$, Qidong Tai et al. demonstrated a strategy by adding different antioxidant hydroxyl-benzene sulfonic acids or salts into $\mathrm{SnCl}_{2}$ which contains perovskite precursor solutions and that leads to encapsulate the perovskite [54]. Zhengqi Shi and Ahalapitiya H. illustrated that there are many types of developed fabrication approaches of PSCs and categorized them into four main methods: one-step, two-step, vapor-assisted solution, and thermal vapor deposition which has the best PCE of $17.6 \%$. It was expected that solution-based approaches like spin coating with a mixed perovskite phase achieved the desired high PCE of $22.1 \%$ as mentioned in the record and PCE for the stable device was $21.2 \%$. Furthermore, they fabricated the dense compact layer of $\mathrm{TiO}_{2}$ by spray pyrolysis process to build a planar structure [19]. Jie Wang studied the deposition of the perovskite layer in 2D lead-free based- PSC. The deposition could be by using one of these methods: Thermal injection, solution processing, and exfoliation method [55].

\subsection{Mesoporous Perovskite Solar Cell}

In 2015, Sang Do Sung et al. fabricated lead halide PSC with mesoporous structure $\mathrm{FTO} / \mathrm{TiO}_{2} / \mathrm{mp}$ $\mathrm{TiO}_{2} / \mathrm{CH}_{3} \mathrm{NH}_{3} \mathrm{PbI}_{3} /$ Spiro /Au. Beginning with the compact layer $\mathrm{TiO}_{2}$, The Ti film with a thickness of 10 nm was deposited on FTO by using the radio frequency magnetron sputtering system. Next, spin coating of an
$\mathrm{mp}-\mathrm{TiO}_{2}$ layer for $30 \mathrm{~s}$ at $5000 \mathrm{rpm}$ was performed using the prepared pastes of $\mathrm{TiO}_{2}$. Then, the $\mathrm{CH}_{3} \mathrm{NH}_{3} \mathrm{PbI}_{3}$ layer was deposited by the two-step method and the HTL was spin-coated for $30 \mathrm{~s}$ at 4000 rpm. According to the Au layer "BC", the deposition was made by a thermal evaporator. They discovered that the PSC-50 which employs NP50 (diameter of $\mathrm{TiO}_{2}$ nano-porous NPS $=50 \mathrm{~nm}$ ) gains the largest PCE of $17.19 \%$ with $V_{\mathrm{OC}}$ of $1.049 \mathrm{~V}$, FF (Fill Factor) of 0.759 , and $J_{\mathrm{SC}}$ of $21.58 \mathrm{~mA} \mathrm{~cm}^{-2}$ as shown in Table. 1 [23].

Table 1. $J-V$ curve parameters of several perovskite solar cells employing $\mathrm{TiO}_{2}$ NPs of various sizes [23].

\begin{tabular}{|l|l|l|l|l|}
\hline $\begin{array}{l}\text { Perovskite } \\
\text { solar cells }\end{array}$ & $\begin{array}{l}\text { PSC- } \\
65\end{array}$ & $\begin{array}{l}\text { PSC- } \\
50\end{array}$ & $\begin{array}{l}\text { PSC- } \\
40\end{array}$ & $\begin{array}{l}\text { PSC- } \\
30\end{array}$ \\
\hline $\begin{array}{l}J_{s c} \\
\left(\mathrm{~mA} / \mathrm{cm}^{2}\right)\end{array}$ & 21.27 & 21.58 & 21.45 & 21.61 \\
\hline$V_{o c}(\mathrm{mv})$ & 1005 & 1049 & 1029 & 995 \\
\hline FF $(\%)$ & 72.35 & 75.94 & 69.74 & 66.59 \\
\hline$\eta(\%)$ & 15.47 & 17.19 & 15.24 & 14.32 \\
\hline
\end{tabular}

Zhengqi Shi and Ahalapitiya H. Jayatissa reported that the $\mathrm{TiO}_{2}$ "ETL" could be either compact/mesoporous (mp) layer in mesoporous structure or one-layer in a planar structure. On the whole, sequential deposition was used to form the bilayer " $\mathrm{TiO}_{2}$ " in which spray pyrolysis process for the deposition of the dense $\mathrm{TiO}_{2}$ compact layer and then the spin coating for the $\mathrm{mp}-\mathrm{TiO}_{2}$. In addition, they summarized HTMs into three categories: small molecules, organic polymers, and inorganic compounds. While spin-coating is the typical HTM layer fabrication approach and other few reports mentioned other processes as sputtering and spray for only inorganic HTM [19]. Di Zhou et al. reported that $\mathrm{TiO}_{2}$ ETL is the most popular mesoporous material that lets the perovskite nanocrystals go through the pores of mp- $\mathrm{TiO}_{2}$ by solution spin-coating process and composes an interconnected absorbing layer [8].

In 2019, Rui Wang explained the different processing techniques of perovskite material and $\mathrm{TiO}_{2}$ layer. For perovskite material, he mentioned a few information about Spin coating, Dip coating, Two-step deposition, Chemical vapor deposition (CVD), Ink-jet printing, blade coating, and screen-printing methods $[1,56]$. Spray coating in which a nozzle is utilized to disperse tiny droplets of liquid onto the perovskite layer and can be deposited by ultrasonic spraying. The non- 
conventional method, Dip coating, is used to form the meniscus edge, pulls a substrate out of the ink of precursor, and sheers a cover plate over the deposited substrate.

A two-step deposition process in which the lead halide thin film is deposited at first, then it reacts with organic halide salts and converts to perovskite. Chemical vapor deposition process (CVD) was used to deposit thin films of $\mathrm{FAPbI}_{3}$ on $5 \mathrm{~cm} * 5 \mathrm{~cm}$ substrate and to synthesize $12 \mathrm{~cm}^{2}$ modules with a PCE of $9 \%$. Ink-jet process where printing nozzles are used for dispersion of the precursor ink drops with good control of trajectory and drop size. The inkjet printing method is used to fabricate PSCs with small areas $\left(0.04 \mathrm{~cm}^{2}\right)$ Blade coating method achieved PCE 19\% and the screen-printing technique owes a perfect ability of patterning with lateral resolution 75-100 micrometer. For the $\mathrm{TiO}_{2}$ layer, there are three strategies for deposition which are used in a wide range.

A spin-coating process where the colloidal dispersion of nano-sized $\mathrm{TiO}_{2}$ has occurred, then thermal treatment of (Titanium isopropoxide, Titanium source: $\mathrm{TiCl}_{4}$, Tetra-n-butyl-titanate) is made. Spincoating of the precursor solutions (Titanium) is also performed following with thermal treatment of (Titanium isopropoxide, Titanium source: $\mathrm{TiCl}_{4}$, Titanium diisopropoxide bis(acetylacetonate) and Spray pyrolysis deposition of (Titanium source: Titanium diisopropoxide bis (acetylaceto nate).

In perovskite solar cells, sintering approaches of low temperature were recently reported to form an effective $\mathrm{TiO}_{2}$ layer. An mp- layer is deposited onto the compact layer using screen printing, spin coating, electrospinning, or magnetron sputtering. The fabrication of a compact $\mathrm{TiO}_{2}$ layer using either a solgel method or spray pyrolysis on glass substrates. To form highly and uniformed quality compact film of $\mathrm{TiO}_{2}$ over large areas, vacuum-based methods, like electron-beam evaporation, RF sputtering, and also thermal oxidation of a sputtered titanium film are used, but high temperature is needed for annealing. In addition, the deposition of the $\mathrm{TiO}_{2}$ compact layer is occurred by low-temperature techniques including electrodeposition and deposition of atomic layer.

For the ETM layers $\mathrm{ZnO}$ and $\mathrm{SnO}_{2}, \mathrm{ZnO}$ can be deposited by multiple processing techniques like solgel, RF sputtering, hydrothermal, ALD, and chemical bath technique and $\mathrm{SnO}_{2}$ is also synthesized via processing routes and nanoparticles at low-temperature utilizing the as-prepared sol-gel derived tin precursors and atomic layer deposition process [1].

\subsection{Ferroelectric Metal- Halide Perovskite Solar}

\section{Cell}

In 2015, Bo Chen fabricated (1_x) $\mathrm{BaTiO}_{3}$ $\mathrm{xBiFeO}_{3} \quad(\mathrm{x}=0.725) \quad(\mathrm{BT}-\mathrm{BFO})$ by the solid-state reaction process to form ferroelectric solar cell. He performed a spin coating process for the deposition of the compact layer " $\mathrm{TiO}_{2}$ " onto FTO layer and the $\mathrm{PbI}_{2}$ infiltrated the $\mathrm{mp}-\mathrm{TiO}_{2}$ films $(260 \mathrm{~nm})$ to synthesize ferroelectric planar and mp-solar cells. Then, Lead halide perovskite was synthesized by spin-coating procedure with two steps. For the HTM layer, the spin coating procedure was used for the deposition of 300 $\mathrm{nm}$ thickness for $30 \mathrm{~s}$ at $3000 \mathrm{rpm}$. To complete the device, $100 \mathrm{~nm}$ of Au was thermally evaporated on the spiro-MeOTAD- layer. The PCE was achieved 13.01 $\%$ for MPSCs and $8.31 \%$ for PPSCs [57]. In 2018, Ming-Zi Wang et al. synthesized ferroelectric PSCs with the structure FTO glass/ $\mathrm{PTO} / \mathrm{CH}_{3} \mathrm{NH}_{3} \mathrm{PbI}_{3}$ /spiroOMeTAD/Au where PTO $\left(\mathrm{PbTiO}_{3}\right)$ film acts as the ferroelectric control layer and ESL (Tunable electron selective layer). The PTO thin film as ESL is deposited over FTO layer as shown in Fig.12. PTO layer is fabricated by a popular sol-gel spin-coating deposition. The PSC based on PTO reached PCE exceeding $12.28 \%$ upon preliminary optimization [58].

\section{Modelling and Simulation of Metal-Halide Perovskite Solar cells}

Numerical simulation is an important and necessary technique to predict the performance of solar cell parameters and to give the physical guidance for optimization of various geometrical and technological parameters of solar cells [10]. In addition, it can present the SC physical operation and its proposed physical model.

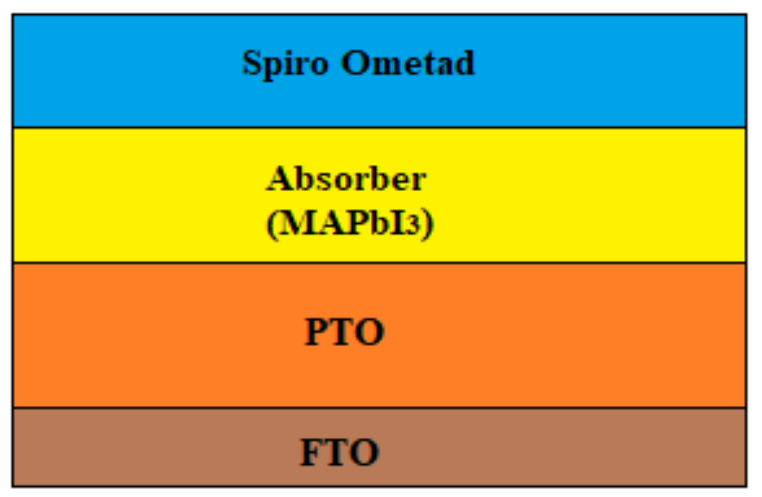

Fig. 12 Structure schematic diagram of perovskite solar cell device using PTO as an ESL. Reproduced from [58]. 
This model is an important method to understand the device operation and the effect of the device parameters in the performance and physical operation of SC instantly without waiting a long time or spending money before seeing a result [7]. Some previous studies predicted and used some solution methods according to their needs such as Sumanshu Agarwall and Pradeep R. Nair, In 2014. They used Poisson equation and Drift Diffusion (DD) self-consistent solutions to study the device characters under illuminated and dark conditions. They performed a good calibration of a comprehensive modelling framework with previous experimental results for understanding/interpreting PSCs. This cell was composed of main three materials $\left(\mathrm{TiO}_{2}\right.$ as ETL - perovskite material as absorber- SpiroOMetad as HTL) which were sandwiched between FC and BC. They discussed more optimization plans based on analytical modelling and numerical simulations. The analytical models predicted that the built-in potential could be lower than the open-circuit voltage $\left(V_{o c}\right)$. Results assured that efficiency $>20 \%$ could be obtained after optimizing the used cell [59]. Others used 3D- DD model for investigation and quantifying the effect of Ferroelectric mesoscale polarization on the PSCs performance. Tejas S. Sherkar and L. Jan Anton Koster have already used this model on the lead trihalide PSCs to characterize the SC operation. For the mesoscale ferro-electrical energy, they incorporated domains named polarization strength $(P)$ in 3D space which formed several microstructures or polarization landscapes.

The microstructures study together with highly ordered polarized domains illustrated that recombination and charge transport in the cell depends strongly on the landscape of polarization viz. the domain size and the domain boundaries orientation [43]. On the other hand, Ming-Zi Wang et al., hoped to understand the physical mechanism of the carrier transport which is happened by the ferroelectric polarization in the electronic heterostructure of $\mathrm{PTO} / \mathrm{CH}_{3} \mathrm{NH}_{3} \mathrm{PbI}_{3}$ but they used Density Functional Theory (DFT) methods to get an overall picture of the electron transport mechanism with various ferroelectric polarization through the interface between the perovskite and PTO. They designed and synthesized PSCs with PTO as ESL in the laboratory. They presented the impact of PTO for charge transfer and e$\mathrm{h}$ separation. They revealed that the ferroelectric layer PTO can increase the PCE besides to adjusting the photocurrent by tuning its ferroelectric polarization. The cells achieved $\approx 12.28 \%$ PCE upon first optimization. The stable PCE of the best SC was achieved at $0.62 \mathrm{~V}$ (max point of power). It illustrated that the synergistic impact of alignment of type II band and the direction of certain ferroelectric polarization provided the effective electrons extraction from the light absorber whereas, the recombination of photogenerated e-h pairs reduced [58]. In addition, Esteban Velilla et al., and his team in 2018 aimed to determine the diode saturation current, photo-generated current, ideality factor, series, and shunt resistances attached to the one-diode model for PPSCs. The Nelder-Mead method combined with a Genetic Algorithm helped them to reduce the mean square error between the circuital model results and the $I-V$ curve data of the using cells. They fabricated and characterized the cells with approximately $1 \mathrm{~cm}^{2}$ active area at ideal test conditions. The efficiencies extended from 4.6 to $12.2 \%[60]$.

In 2018, Iman Moein et al., suggested two timedependent modelling approaches for PSC characteristics variation under stress situations. The approach\#1 followed Sah-Noyce-Shockley (SNS) model based on SRH generation/ recombination across the width of depletion (W) of pn junction and the approach \#2 was based on thermionic emission (TE) model for Schottky diodes. The time-dependent defect generation in $\mathrm{W}$ of the junction was used for the connection between these approaches and time variation. The two models have fitted with previous experimental results. It was found out that every model has an excellent illustration for degrading the device metrics such as efficiency and current density by time during the effect of stress conditions. The TE model is less reliable than the SNS model for solar cells at least. They supposed that the defect density of the deep acceptor was a time-dependent parameter as it increased exponentially by time under stress and this changed the electric field, depletion width, and current density. The generation of defects took place in normal or most stressing process conditions and this would make the modelling non-static. The fitting of the used models with previous experimental data illustrated that TE theory or SNS theory fitted with a portion of the data and didn't explain the whole data of all times. This point assured the big importance of a time-dependent approach in a model in the solar cells' physics [61].

Numerous simulation models were used in the PVs technology (COMSOL, AMPS (Analysis of Microelectronic and Photonic Structure), MULTIPHYSICS, SCAPS (Solar cell Capacitance Simulator), GPVDM, TiberCAD and SILVACO, Matlab, wxAMPS) [6]. Herein, a review about the most popular modelling and simulation techniques of different types and structures of metal halide PSCs to predict different needs of studies. 


\subsection{MATLAB}

Gagandeep et al., used MATLAB for PSC modelling. The PSC is considered as a single diode model incorporating as shown in Fig.13.They applied some theoretical researches to understand the perovskites working procedures for SC applications. Analysis of the variation of efficiency $(\eta)$ for several values of shunt resistance (RP) keeping the series resistance (RS) constant and vice versa was executed. An efficiency of $11.25 \%$ was achieved for $\mathrm{CH}_{3} \mathrm{NH}_{3} \mathrm{PbI}_{3}$ based PSC. The numerical results are compatible with the experimental data and the previous theoretical results [62].

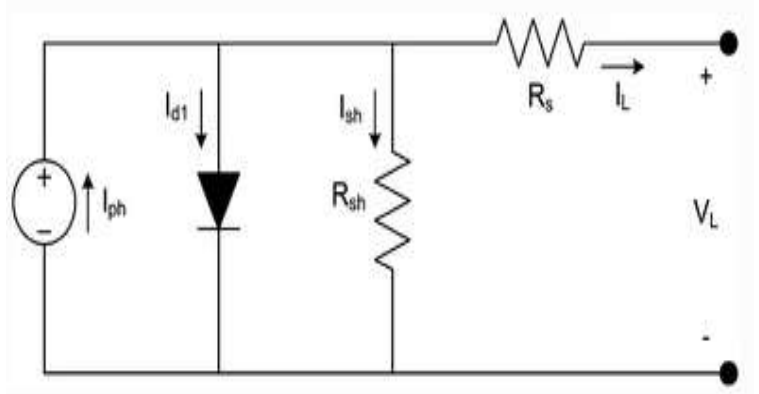

Fig. 13 The single diode model of solar cell [63].

\subsection{AMPS-1D}

Feng Liu et al. designed a high-efficiency PSC thorough examination of the material influences on device parameters. Therefore, they used AMPS-1D to simulate the PSCs based on this planar heterojunction $\mathrm{TiO}_{2} / \mathrm{CH}_{3} \mathrm{NH}_{3} \mathrm{PbI}_{3} /$ Spiro. Simulation results illustrated that the PCE performance depends strongly on absorber defect density, absorber thickness, the BC work function, HTL hole mobility, and HTL acceptor density. Since the hole mobility and the acceptor density values of Spiro-ometad increase, the $J$ - $v$ curve improves at each value. Strikingly, an efficiency of more than $20 \%$ was achieved under moderate conditions of simulation [6].

\subsection{WXAMPS}

In 2015, Yan Wang and his group used a wxAMPS tool which is the updated version of AMPS for the simulation of solar cells. They performed modelling of LHPSCs with the planar structure TCO $/ \mathrm{NiO}_{\mathrm{x}} / \mathrm{CH}_{3} \mathrm{NH}_{3} \mathrm{~Pb}_{3-\mathrm{x}} \mathrm{CI}_{\mathrm{x}} / \mathrm{PCBM} / \mathrm{Al}$ ) based on inorganic HTMs. They studied the function of the inorganic HTL and discussed how the band offset between absorber/inorganic HTM layers affected the efficiency until they achieved PCE of $9.88 \%$ using $\mathrm{NiO}_{\mathrm{x}}$ as HTL. Using $\mathrm{Cu}_{2} \mathrm{O}$, the high mobility material, instead of
$\mathrm{NiO}_{\mathrm{x}}$ resulted in PCE of $13.6 \%$ [35]. Despite the popularity of spiro-OMETAD as HTM in PSCs, it is very expensive. To design a highly performed PSC with decreasing the cost of manufacturing, it is necessary to replace spiro-OMETAD with copper oxide and other HTMs such as Cuie, $\mathrm{CuSCN}$, and $\mathrm{NiO}$ in the planar architecture Glass/FTO/TiO $/$ $\mathrm{CH}_{3} \mathrm{NH}_{3} \mathrm{PbI}_{3}$ / spiro-OMETAD/Au as shown in Fig.14. In 2015, Mohammad I. Hossain et al., designed the mentioned PSC with the new HTMs and simulated them by wxAMPS and SCAPS. This software makes a numerical solution through solving the three basic equations namely continuity and Poisson equations which control the carrier transport. The simulations achieved PCE larger than $24 \%$ for $\mathrm{Cu}_{2} \mathrm{O}$ [33].

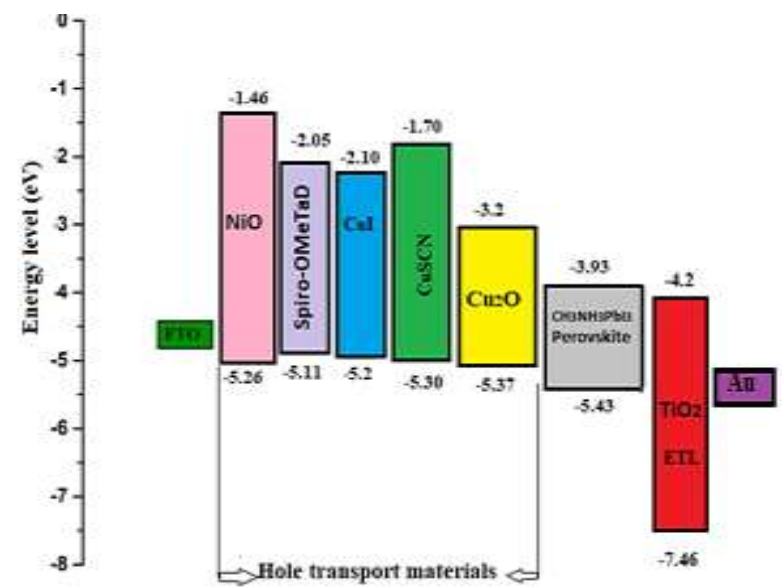

Fig. 14 Energy band alignment of lead iodide perovskite and four different HTMs. Reproduced from [33].

The removal of HTL from the standard sandwiched configuration leads to the poor performed device as shown in Fig.15. The HTL-free PSC mechanism is also still unclear. In 2016, Tianyue Wang et al., and his team used wxAMPS-1D to study this HTL-free PPSCs $\mathrm{TiO}_{2} / \mathrm{MAPbI}_{3} /$ spiro-OMeTAD with the suitable thickness and doping of absorber and absorber/bc band alignment. After optimization, an efficiency exceeding $17 \%$ is obtained [32].

\subsection{SILVACO ATLAS}

Laurent Pedesseau et al. studied the dielectric profiles of 2D, 2D-3D and 3D Hybrid Organic Perovskites (HOP) for the PPSCs FTO/TiO $/ \mathrm{MAPbI}_{3} /$ HTM/Au and suggested a technique to descript them. This technique exceeded the standard approximation for dielectric constant profiles with abrupt interfaces 
and was proposed using DFT calculations method. Simulation was by Silvaco to get a numerical solution of holes and electrons continuity equations which are coupled with Poisson's equation under steady state conditions. It achieved initial optimized efficiency PCE of $17 \%$ and it was compatible with the experimental results [65].
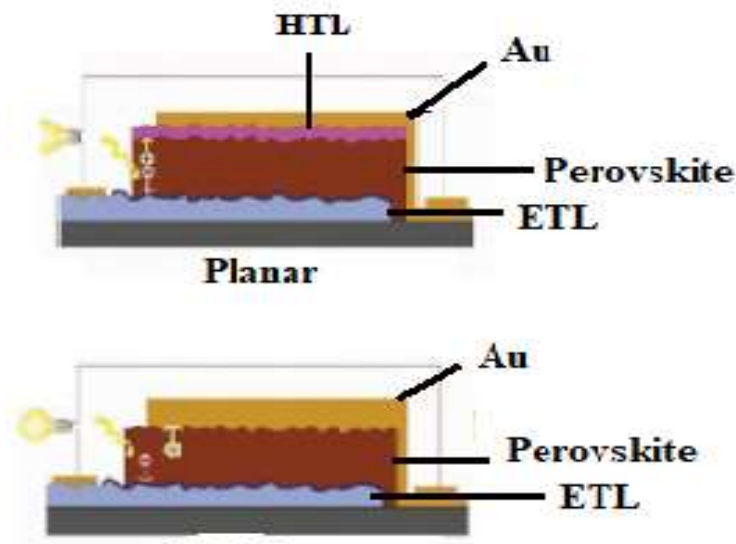

HTL free

Fig. 15 Schematic architectures (b) of the standard planar perovskite solar cell and the derived HTL-free device model [64].

In 2017, Masood Mehrabian and Sina Dalir used SILVACO ATLAS software to simulate the new modeled sensitized PSC with planar architecture ITO/TiO $/$ Perovskite/ PEDOT/Au. They focused on carrier dissociation, photo-current creation, and photogeneration processes which provided hopeful results of $70.10 \%$ FF and PCE of $11.73 \%$. There was a perfect match between the simulated $J-V$ curve and the experimentally obtained results that can be great proof of the simulation accuracy [20] as shown in Table.2.

Rahul Pandey et al. in 2019 studied the potential alternatives ETMs for PSCs. Reduced cerium oxide $\left(\mathrm{CeO}_{\mathrm{x}}\right)$ with multiple oxygen compositions was used as ETM layer in the planar architecture FTO (100 nm) /ETL (60 nm n-type $\mathrm{CeO}_{\mathrm{x}}$ )/ interface layer (10 nm ntype $\mathrm{PCBM}$ )/ absorber (250 nm $\left.\mathrm{CH}_{3} \mathrm{NH}_{3} \mathrm{PbI}_{3}\right) / \mathrm{HTL}$ (150 nm spiro Ometad) with CNT.

Table 2. Photovoltaic parameters obtained from simulation compared to experimental data [20].

\begin{tabular}{|l|l|l|l|l|}
\hline Parameters & $\begin{array}{l}\text { PCE } \\
(\%)\end{array}$ & $\begin{array}{l}J_{s c} \\
\left(\mathrm{~mA} / \mathrm{cm}^{2}\right)\end{array}$ & $\begin{array}{l}\text { Fill } \\
\text { Factor } \\
(\%)\end{array}$ & $\begin{array}{l}V_{o c} \\
(\mathrm{v})\end{array}$ \\
\hline Experimental & 11.75 & 15.93 & 72.34 & 1.02 \\
\hline Simulation & 11.73 & 15.92 & 70.10 & 1.02 \\
\hline
\end{tabular}

Analysis of the cell with PCBM interface layer thickness which was sandwiched between the absorber perovskite layer and ETL was also performed. Research with a lot of details has been executed such as the $\mathrm{CeO}_{\mathrm{x}}$ mobility because of the hopping mechanism of small polaron at the different $\mathrm{X}$ compositions and the influence of doping concentration's variance of $\mathrm{CeO}_{\mathrm{x}}$ and PCBM. TCAD (Technology Computer-Aided Design) Silvaco ATLAS simulated the cell and got an optimal efficiency of $18.2 \%$. After that, they incorporated the CNT layer between HTL and perovskite to recover the shortcomings due to moisture and hysteresis stability which offered PCE $18.6 \%$ [34].

In 2020, Deepak Kumar Jarwal et al. used TCAD to get the best PCE for the LHPSC with the structure FTO/TNRs(ETL)/ CH3NH3PbI3 /PTAA(HTL)/Pd. Various parameters such as ETL, HTL, and absorber thicknesses were investigated during simulation. It was observed that the PCE was decreased when ETL thickness was more than $500 \mathrm{~nm}$. The Maximum simulated PCE reached $15.69 \%$ at $100 \mathrm{~nm}, 500 \mathrm{~nm}$, and $350 \mathrm{~nm}$ of the HTL, ETL, and absorber against the experimental PCE of $15.04 \%$. The two results were matched very well [66].

\subsection{Tiber Cad}

Alessandro Pecchiaet al. utilized Metropolis Monte Carlo simulations to build minimum energy configurations by electrostatic coupling of rotating dipoles coupled with every unit cell of $\mathrm{CH}_{3} \mathrm{NH}_{3} \mathrm{PbI}_{3}$ perovskite crystal. Anti-ferroelectric order with shortrange was found. They observed domains with nanoscale $(8-10 \mathrm{~nm})$ affected the device's electrostatics. For studying the actual function of nano-domains in the I-V characteristics, particularly concentrating on recombination losses $(\mathrm{R})$ and charge separation, they associated DD simulations to the used models. The DD equations were discretized with finite elements (FEM) by Tiber CAD simulation. The Lambert-Beer model computed the generation. R accounts for direct Shockley-Read-Hall (SRH) or defect-mediated recombination losses. The electrons and holes flow into various nano-domains with different pathways of current. They abbreviated their study into an important point that even antiferroelectric ordering could finally lead to an increase of PCE due to the forming of good current percolation patterns along edges of the domain and the reduction of trap-assisted $R$ [44].

Daniele Rossi et al. explained in detail the influence of ferroelectric polarization patterns in thin 
films of $\mathrm{MAPbI}_{3}$ on the solar cells' J-V characteristics. The simulations depended on a discretized FEM of the DD equations and also considered that the polarization pattern is derived experimentally from force micrographs with piezo-response. Tiber CAD simulator with FEM was used to discretize the Poisson equations and DD. Lambert-Beer model calculated the profile of charge carrier generation supposing illumination from the bottom (anode contact). They included direct $\mathrm{R}$ and defect-mediated SRH in the model by using $\mathrm{MAPbI}_{3}$ standard parameters. Despite the weak magnitude of characteristic polarization of ordered ferroelectric domains, it improved the PCE and was necessary to reproduce the $J$ - $V$ experimental characteristics. The used PPSCs with the architecture ITO/PEDOT: $\quad$ PSS/MAPbI ${ }_{3} \quad(\mathrm{Cl}) / \mathrm{PC}_{71} \mathrm{BM} / \mathrm{BCP} / \mathrm{Ag}$ and reached to PCE of $15 \%$. The experimental and simulated multi-grain results at $P_{x y}=0.2 \mathrm{uC} \mathrm{cm}^{-2}$ provide a perfect match [67].

D. Rossi et al. explained how 3-D ferroelectric domains in $\mathrm{MAPbI}_{3}$ influenced the performance of PSC. Tiber CAD simulator executed calculations using a 3D- DD model, which simulates the light absorption and charge carrier transport with the local polarization. They illustrated that the polarization domains affected strongly the separation of charge carriers, leading to a decrease in current routs formation and e-h recombination at interfaces [42].

\subsection{SCAPS}

SCAPS are supported physically by solving the 1D-general equations for semiconductors that depend on popular continuity equation, transport equation, Poisson's equation, and also one of many recombination mechanisms [3, 7]. Through device simulation and theoretical analysis of SCAPS, researchers study the effects of doping concentration and the thickness of perovskite on the performance of solar cells [2] as shown in Fig.16. SCAPS-1D simulation helps us to know the band offsets effects in the PPSCs, the influence of two types of band offsets: the VB (Valence Band) offset of absorber/HTM and CB (Conduction Band) offset of buffer (blocking layer)/absorber substrate [68]. Besides the effects of defect density, thickness, the doping density of the absorber layer, carriers' diffusion length, and electron affinity of HTM and ETM layers on the PSCs performance are also investigated by Scaps [69].

In 2014, Fahad H Alharbi et al. used different HTM layers including CuI, spiro-OMeTAD, NiO, and CuCSN to improve durability and efficiency of the PPSC with the structure FTO $/ \mathrm{TiO}_{2} /\left(\mathrm{CH}_{3} \mathrm{NH}_{3}\right) \mathrm{PbI}_{3} /$ $\mathrm{Cu}_{2} \mathrm{O} / \mathrm{Au}$ as shown in Fig.17. SCAPS simulated the cell to study the key parameters and achieved PCE of $19.43,21.97,19.19$ and $22.03 \%$, respectively [5]. In 2015, Takashi Minemoton and Masashi Murata investigated TCO $\left(\mathrm{SnO}_{2}: \mathrm{F}\right) /$ buffer $\left(\mathrm{TiO}_{2}\right) /$ Interface Defect Layer (IDL1)/ $\left(\mathrm{CH}_{3} \mathrm{NH}_{3} \mathrm{PbI}_{3-\mathrm{x}} \mathrm{Cl}_{\mathrm{x}}\right)$ / (IDL2)/HTM (Spiro-OMeTAD) and simulated it by SCAPS-1D to know the band offsets effects of the PPSCs, the influence of two types of band offsets, the VB offset of absorber/HTM and CB offset of buffer (blocking layer)/absorber substrate [30].

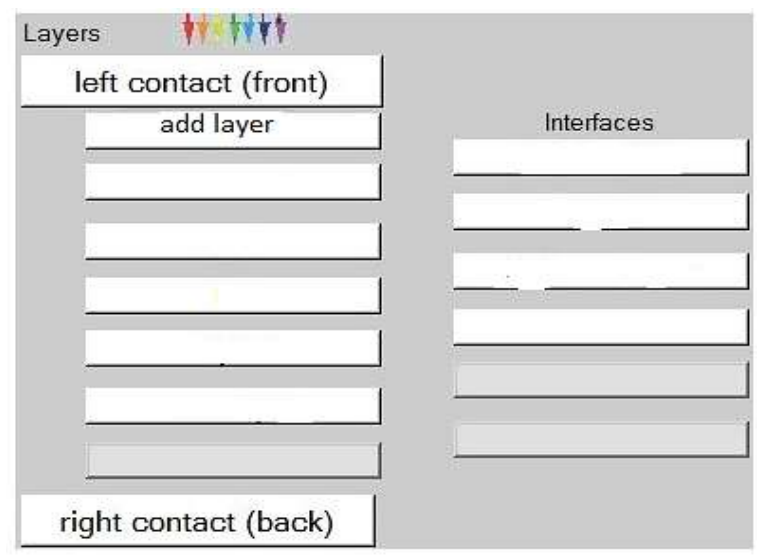

Fig. 16 SCAPS-1D definition panel [7].

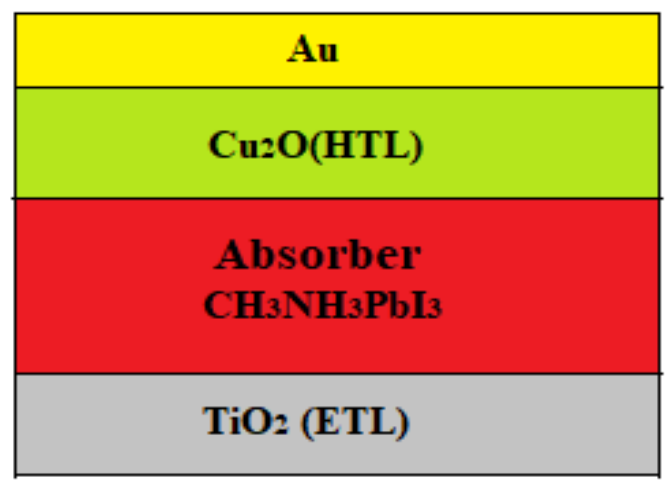

Fig. 17 Structure schematic diagram of perovskite solar cell. Reproduced from [5].

In 2016, Hui-Jing Du et al. performed device simulation and theoretical analysis to study the numerous parameters that affected on the performance of $\mathrm{CH}_{3} \mathrm{NH}_{3} \mathrm{SnI}_{3}$ based PSC with the architecture glass layer/ TCO/buffer layer $\mathrm{TiO}_{2}$ (ETM)/absorption layer $\mathrm{CH}_{3} \mathrm{NH}_{3} \mathrm{SnI}_{3} /$ (HTM) spiro-OMeTAD /metal back contact. The simulation illustrated that adjusting the absorber doping concentration, the HTM and buffer electron affinities and the defect interface can improve the performance of solar cell to some extent as shown in Table.3.The analysis has been done by the SCAPs1D simulator. The research of defect density influence on SC performance was depended on the SRH 
recombination model. After optimization of all parameters, the results were very hopeful with PCE of $23.36 \%$ [22]. In the same year, Shubhra Bansal, Puruswottam Aryal discovered several ETM and HTM alternative layers for $\mathrm{CH}_{3} \mathrm{NH}_{3} \mathrm{PbI}_{3}$ based PPSCs and used SCAPS -1D for simulation.

Table. 3 Final optimized parameters of $\mathrm{CH}_{3} \mathrm{NH}_{3} \mathrm{SnI}_{3}$ PSC [22].

\begin{tabular}{|l|l|l|l|}
\hline $\begin{array}{l}\text { Optimized } \\
\text { parameters }\end{array}$ & HTM & Buffer & $\begin{array}{l}\mathrm{CH}_{3} \mathrm{NH}_{3} \mathrm{SnI} \\
3\end{array}$ \\
\hline $\begin{array}{l}\text { Thickness } / \mathrm{n} \\
\mathrm{m}\end{array}$ & None & None & 600 \\
\hline $\mathrm{N}_{\mathrm{t}} / \mathrm{cm}^{-3}$ & None & None & $1.0^{*} 10^{15}$ \\
\hline $\mathrm{N}_{\mathrm{A}} / \mathrm{cm}^{-3}$ & None & None & $1.3^{*} 10^{16}$ \\
\hline$\chi / \mathrm{eV}$ & 2.6 & 4.0 & None \\
\hline
\end{tabular}

Due to the high electron affinity and tunable band gap of $\mathrm{ZnOS}$, it is considered a perfect alternative to $\mathrm{TiO}_{2}$. In addition, $\mathrm{CsSnI}_{3}$ and $\mathrm{NiO}$ were suitable potential replacements for Spiro-OMeTAD to offer stability in this structure $\mathrm{TiO}_{2}$ (ETL) $/ \mathrm{CH}_{3} \mathrm{NH}_{3} \mathrm{PbI}_{3} /$ Spiro-OMeTAD (HTL). PCEs are 20.17, 20.30, 20.67 and $20.65 \%$ for the combinations $\mathrm{TiO}_{2}-$ Spiro, ZnoS-Spiro, $\mathrm{TiO}_{2}-\mathrm{NiO}$ and $\mathrm{TiO}_{2}-\mathrm{CsSnI}_{3}$, respectively [70].

In 2017, Nandi Wu et al. revealed some factors that limited the FF and $V_{O C}$ and how they correlated to the luminescence signal emission of this PPSC FTO/compact $\mathrm{TiO}_{2} / \mathrm{MAPbI}_{3} /$ spiro/ Au by coupling the device modelling with experimental measurements. They used the most popular simulator" SCAPS" for modelling and simulation. These measurements illustrated the benefit of luminescence to discover the contributions of shunt resistance $\left(R_{s h}\right)$, series resistance $\left(R_{s}\right)$, and non-ideal recombination (SRH) to the lowering of $V_{O C}$ and FF below the theoretical limits [71]. Besides to Hui-Jing Du's group (2017) that designed a new $(\mathrm{p}-\mathrm{i}-\mathrm{n})$ PPSC with the architecture glass layer/TCO / $\mathrm{CH}_{3} \mathrm{NH}_{3} \mathrm{PbI}_{3}$ n-type doping substrate (ETM)/ $\mathrm{CH}_{3} \mathrm{NH}_{3} \mathrm{PbI}_{3}$ i-type (absorption layer)/ $\mathrm{CH}_{3} \mathrm{NH}_{3} \mathrm{PbI}_{3}$ p-type doping substrate (HTM)/metal back contact and simulated it by SCAPS-1D. The impacts of the band gap width, the thickness, and the doping concentration of $\mathrm{p}, \mathrm{i}$, and $\mathrm{n}$ layers on the solar cells' performances were also studied. The results showed that the $\mathrm{p}$ - and $\mathrm{n}$ - doping perovskite layers work very well either as absorber layer or transporting layer. After optimizing the mentioned parameters, the cell achieved these hopeful results: the $V_{o c}$ of $0.956 \mathrm{~V}$, $J_{s c}$ of $32.47 \mathrm{~mA} / \mathrm{cm}^{2}$, PCE of $25.843 \%$, and FF of $83.278 \%$ [68]. The previous studies illustrated that using different layer thicknesses and changing temperature affected the PCE. Therefore, in 2018, Anurag Sahu and Ambesh Dixit studied this inverted planar PSCs which is considered ETL free device BC I FTO $\left(\mathrm{SnO}_{2}: \mathrm{F}\right) / \mathrm{CH}_{3} \mathrm{NH}_{3} \mathrm{PbI}_{3-\mathrm{x}} \mathrm{Cl}_{\mathrm{x}} /(\mathrm{NiO}$ or spiro MeOTAD) /Ni/ TCO by SCAPS and optimized the cell for various thicknesses. Then, the optimized devices were studied against changes in $\mathrm{CB}, \mathrm{VB}$ offsets, and operational temperature. SCAPS considered IDL1 and IDL2 as a respective interface that referred to interface carrier recombination at absorber/HTM and absorber/TCO interfaces and solved primarily two coupled equations with PCE of 22.25, $17.74 \%$ for bulk layers [31].

There was a dire demand to find a stable and inorganic alternative HTM to the popular used HTM "Spiro-MeOTAD", to be used in PSCs with their maximum Capability. Consequently, in 2018, Syed Zulqarnain Haider et al. chose a CuI as HTM in lead halide PSC with the planar heterojunction structure glass / $\mathrm{TCO} / \mathrm{TiO}_{2}$ (ETM) / absorber layer / CuI (HTM) / BC. Then, they performed a comprehensive device simulation using SCAPS to study numerous possible parameters. To determine the defect density effect which affects the PSC performance. To determine the defect density effect on PSC performance, SRH recombination model was used. Doping density and hole mobility of HTM layer was also examined. PCE of the optimized cell achieved $21.32 \%$ [69]. Sonu Bishnoi and Saurabh Kumar Pandey et al. (2018) also performed an overall numerical analysis using SCAPS for a lead-free PSC. To optimize the PCE, several design strategies have been submitted. The two configurations' types of $\mathrm{Pb}$ free $\quad\left(\mathrm{La}_{0.7} \mathrm{Sr}_{0.3} \mathrm{MnO}_{3} / \mathrm{Nb}: \quad \mathrm{SrTiO}_{3} \quad\right.$ and $\left.\mathrm{La}_{0.7} \mathrm{Sr}_{0.3} \mathrm{MnO}_{3} / \mathrm{ZnO}\right)$. This study illustrated that all PV parameters depended on the band gap, thickness, defect density, and light illumination. The desired thickness of absorber and buffer is $4 * 10^{-6}$ and $0.5 * 10^{-}$ ${ }^{6} \mathrm{~m}$ with free defect density and $1.4 \mathrm{eV}$ energy gap for the absorber at room temperature. The used PSC were simulated and achieved PCE of $32 \%$ at $350 \mathrm{~nm}$ and $11 \%$ at $600 \mathrm{~nm}$ wavelengths [72]. In 2018, FAISAL BAIG et al. simulated $\mathrm{MASnI}_{3}$ based PSCs with $\mathrm{Cd}_{1-}$ ${ }_{x} \mathrm{Zn}_{\mathrm{x}} \mathrm{S}$ as ETM layer and $\mathrm{MASnBr}_{3}$ lead-free as HTM layer with the structure FTO/CdZnS/MASnI $3 / \mathrm{MASnBr}_{3} / \mathrm{BC}$ by SCAPS software. The analysis of the influence of HTM layer band offset was performed. Due to the results, it can strongly affect the SC performance. The impact of two types of transport metals on the performance was also analyzed, showing that the band offset adjusting of the $\mathrm{Cd}_{1-\mathrm{x}} \mathrm{Zn}_{\mathrm{x}} \mathrm{S}$ layer led to PCE of $18.71 \%$ PCE [26]. 
In 2019, Mostafa M. Salah et al. replaced SpiroOMeTAD, the conventional HTM, with $\mathrm{CuI}$ and analyzed it with different ETMs CdS, ZnO, ZnSe, and ZnOS as replacement of $\mathrm{TiO}_{2}$, The traditional ETM. Spiro-OMeTAD and $\mathrm{TiO}_{2}$ have been popular with their sensitivity to light-induced degradation. These cells were stimulated by SCAPS-1D and the effects of the perovskite layer, HTL, and ETL thicknesses on the comprehensive cell performance were also performed. The flat band model was utilized for the interfaces of semiconductor/metal and semiconductor/TCO. The results showed that $\mathrm{ZnOS}$ was the best replacement for $\mathrm{TiO}_{2}$ because of its tunable band gap and high electron affinity. PSC based on lead with CuI as HTM had a good arrangement and was more efficient than the expensive and easily degradable Spiro- OMeTAD. Optimization and simulation of different layers thicknesses were applied and the highest efficiency of $26.11 \%$ is obtained [73]. They also performed a simulation of LHPSCs with various ETMs CdS, ZnO, $\mathrm{ZnSe}$, and $\mathrm{ZnOS}$, and copper oxide as HTM using SCAPS-1D simulator as an alternative to the conventional electron and hole transport materials $\left(\mathrm{TiO}_{2}\right.$ and the high-cost spiro-OMeTAD). The simulated work was calibrated with a previous experimental result for the architecture of FTO $/ \mathrm{ZnO}$ (ETM) / MAPbI3/ Spiro-MeTAD (HTM) /Au (BC). Flat band model for the interfaces was used. They introduced an overall study for optimizing the parameters and features of the PSCs, like the doping concentrations, the thickness, defect density of the perovskite layer, and the bandgap energy. The results revealed that mixed halide metal PSC with $\mathrm{ZnOS}$ as ETM layer and copper oxide as HTM layer achieved improved performance with a PCE up to $30.82 \%$, FF of $87.27 \%$, Voc of $1.250 \mathrm{~V}$, and $J_{s c}$ of $28.25 \mathrm{~mA} / \mathrm{cm}^{2}$ [18].

Ali Husainat et al, (2019) employed SCAPS-1D for PSC modelling. The used SC had a contact layer "Au" with a $5.1 \mathrm{eV}$ work function, Spiro-Ometad as HTM layer, $\mathrm{TiO}_{2}$ as ETM layer, and the absorber layer " $\mathrm{CH}_{3} \mathrm{NH}_{3} \mathrm{PbI}_{3}$ " with various thicknesses extended from $50 \mathrm{~nm}$ to $600 \mathrm{~nm}$. The simulation showed that the optimal thickness of the absorber was $300 \mathrm{~nm}$ and achieved PCE of 20.34\% [7] as shown in Fig.18. Ahmed-Ali Kanoun et al. (2019) performed numerical simulations of PSC performance based on $\mathrm{CH}_{3} \mathrm{NH}_{3} \mathrm{GeI}_{3}$ (Methyl Ammonium Germanium halide) and investigated the influence of different parameters on the performance like defect density, thicknesses of absorber, hole mobility, HTM, and work function of a metal electrode on the charges collection. Furthermore, the simulation of Ge-based PSCs with ETL $\left(\mathrm{TiO}_{2}\right)$,
DPBTTT- 14, and $\mathrm{Cu}_{2} \mathrm{O}$ as HTM layer exhibited PCE of $21 \%$ using SCAPS simulator. The reduction of defect density of absorber is a very critical factor to progress the PSC performance. Since the absorber defect density was increased from $10^{14}$ to $10^{18} \mathrm{~cm}^{-3}$, the PCE dropped from $21 \%$ to $11 \%$ [25].

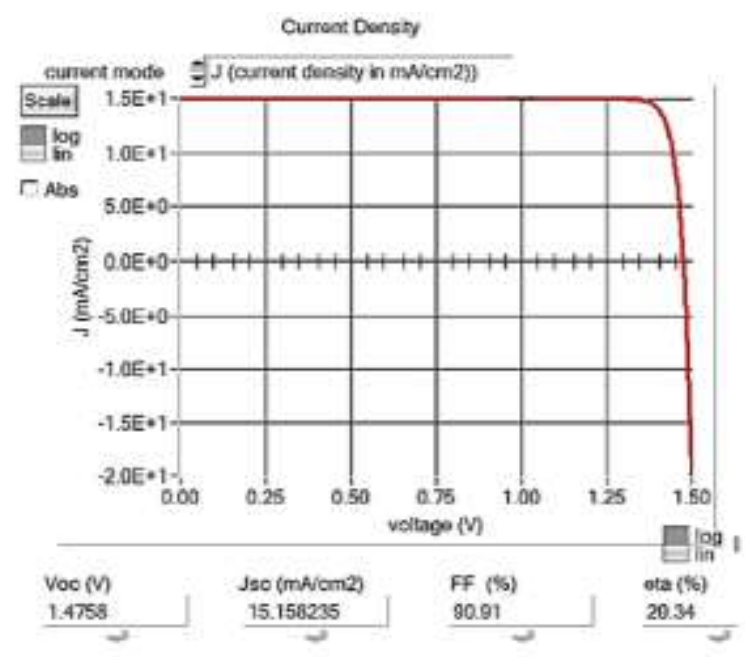

Fig. $18 I-V$ characteristics curve of PSC with $\mathrm{Au}$ contacts [7].

Abou Bakary Coulibaly et al. (2019) designed Snbased PSC model with the structure $\mathrm{TCO} / \mathrm{TiO}_{2}$ as buffer/ $\mathrm{CH}_{3} \mathrm{NH}_{3} \mathrm{SnI}_{3}$ as absorber/ HTM and analyzed it using 1D-SCAPS software. The obtained simulation model would be a good guide to fabricate Sn-based PSC with high PCE because the results indicated that $\mathrm{CH}_{3} \mathrm{NH}_{3} \mathrm{SnI}_{3}$ has been having a great potential to work as an absorber layer with convenient inorganic HTMs such as $\mathrm{Cu}_{2} \mathrm{O}$ with $19.17 \%$ PCE, CuI with $23.25 \%$ PCE $23.25 \%$ and organic HTMs such as spiroOMETAD with $23.76 \%$ PCE and PTAA with $23.74 \%$ PCE [3]. In 2020, Nacereddine Lakhdar and Abdelkader Hima used Scalps for the simulation of the Ge-based PSC with the p-i-n structure TO/PEDOT: PSS /MAGeI3/ PCBM/Ag and obtained PCE of $10.79 \%$. The optimization of different parameters such as diverse layer thickness, HTL, ETL, and absorber layers gave the optimal PCE value of $11.16 \%$. After using C60 as ETL, the PCE reached $13.5 \%$ [74].

\section{Conclusion}

In this review, a thorough study has been performed about the significant progress in the organic-inorganic Perovskite Solar Cells (PSCs) with different structures and using new materials. The possibility of using $\mathrm{Sn}$, Ge instead of Pb-based PSC aiming to avoid instability and toxicity is discussed. In addition, new ETMs (CdS, ZnO, ZnSe, PEDOT: PSS, 
$\mathrm{NiO}_{x}, \mathrm{Cu}_{2} \mathrm{O}$ and $\mathrm{ZnOS}$,et al., ) and HTMs (Cui , NiO , $\mathrm{CsSnI}_{3}, \mathrm{PC}_{71} \mathrm{BM}$, PTAA, and PCBM, et al.,) are presented as alternatives to $\mathrm{TiO}_{2}$ and Spiro-OmeTAD with $\mathrm{ZnOS}$ to be the best replacement for $\mathrm{TiO}_{2}$ because of its tunable band gap and high electron affinity. Perovskite-based on $\mathrm{Sn}$ is considered a promising, reliable material and a good guide to be used in future works with convenient ETMs and HTMs and will have great potential in work. Meanwhile, this review discussed the different PSC models, charge transport mechanisms, their relevance, and the possible improvements towards highly efficient cheap devices. The review also presented various methods of synthesis and fabrication approaches of PSCs with their multiple structures and layers based on recent research over the last years. In addition, modelling approaches and simulation tools were also introduced. These approaches include: (1) the self-consistent solution of Poisson equation and Drift-Diffusion (DD) equations, (2) Density Functional Theory (DFT) methods, (3) Nelder-Mead method combined with a Genetic Algorithm and (4) the two time-dependent modelling approaches. Simulation tools such as COMSOL, AMPS, MULTIPHYSICS, SCAPSGPVDM, TiberCAD and SILVACO, Matlab, and wXAMPS were highlighted.

\section{References}

[1] R. Wang, M. Mujahid, Y. Duan, Z. Wang, J. Xue, and Y. Yang, A Review of Perovskites Solar Cell Stability, Adv. Funct. Mater. , 29 (2019) 1808843. https://doi.org/10.1002/adfm.201808843

[2] X. Liang, C. Ge, Q. Fang, W. Deng, S. Dey, H. Lin, Y. Zhang, X. Zhang, Q. Zhu, and H. Hu, Flexible Perovskite Solar Cells: Progress and Prospects, Front. Mater. , 8 (2021) 634353. https://doi.org/10.3389/fmats.2021.634353

[3] A. B. Coulibaly, S. O. Oyedele, N. R. Kre, and B. Aka, Comparative Study of Lead-Free Perovskite Solar Cells Using Different Hole Transporter Materials, Modelling and Numerical Simulation of Material Science, 9 (2019) 97-107. https://doi.org/10.4236/mnsms.2019.94006

[4] X. Sun, R. Asadpour, W. Nie, A. D. Mohite, and M. A. Alam, A Physics-based Analytical Model for Perovskite Solar Cells, IEEE Journal of Photovoltaics, $5 \quad$ (2015) 1389 - 1394. http://doi.org/10.1109/JPHOTOV.2015.2451000

[5] F. H. Alharbi, M. I. Hossain, and N. Tabet, Perovskite Based Solar Cells: A Milestone towards Cheaper PV Technology, 3rd Int. Symp. Environ. Friendly Energies Appl. EFEA, (2014).
https://doi.org/10.1109/EFEA.2014.7059955

[6] F. Liu, J. Zhu, J. Wei, Y. Li, M. Lv, S. Yang, B. Zhang, J. Yao, and S. Dai, Numerical simulation: Toward the design of high-efficiency planar perovskite solar cells, Appl. Phys. Lett., 104 (2014) 253508. https://doi.org/10.1063/1.4885367

[7] A. Husainat, W. Ali, P. Cofie, J. Attia, and J. Fuller, Simulation and Analysis of Methylammonium Lead Iodide $\left(\mathrm{CH}_{3} \mathrm{NH}_{3} \mathrm{PbI}_{3}\right)$ Perovskite Solar Cell with $\mathrm{Au}$ Contact Using SCAPS 1D Simulator, American Journal of Optics and Photonics , 7 (2019) 33-40. https://doi.org/10.11648/j.ajop.20190702.12

[8] D. Zhou, T. Zhou, Y. Tian, X. Zhu, and Y. Tu, Perovskite-Based Solar Cells: Materials, Methods, and Future Perspectives, Journal of Nanomaterials, (2018) 8148072.

https://doi.org/10.1155/2018/8148072

[9] X. Dai, K. Xu, and F. Wei, Recent progress in perovskite solar cells: the perovskite layer, Beilstein J. Nano-technol., 11 (2020) 51-60.

https://doi.org/10.3762/bjnano.11.5

[10] N. Park, and K. Zhu, Scalable fabrication and coating methods for perovskite solar cells and solar modules, Nature Reviews Materials, 5 (2020) 333-350. https://doi.org/10.1038/s41578-019-0176-2

[11] Y. Wang, Z. Zhang, Y. Lan, Q. Song, M. Li, and Y. Song, Tautomeric Molecule Acts as a "Sunscreen" for Metal Halide Perovskite Solar Cells, Angew. Chem. Int. Ed., 60 (2021) 8673 8677.

https://doi.org/10.1002/anie.202100218

[12] E. Akman, A. E. Shalan, F. Sadegh, and S. Akin, Moisture-Resistant $\mathrm{FAPbI}_{3}$ Perovskite Solar Cell with 22.25\% Power Conversion Efficiency through Pentafluorobenzyl Phosphonic Acid Passivation, Chem Sus Chem, 14 (2021)11761183. https://doi.org/10.1002/cssc.202002707

[13] J. J. Yoo, G. Seo, M. R. Chua, T. G. Park, Y. Lu, F. Rotermund, Y. Kim, C. S. Moon, N. J. Jeon, J. Baena, V. Bulović, S. S. Shin, M. G. Bawendi, and J. Seo, Efficient perovskite solar cells via improved carrier management, Nature, 590 (2021) 587-593.

https://doi.org/10.1038/s41586-021-03285w

[14] K. Valadi, S. Gharibi, R. Taheri-Ledari ,S. Akin, A. Maleki, and A. E. Shalan, Metal oxide electron transport materials for perovskite solar cells: a review, Environmental Chemistry Letters, 19 (2021) 2185-2207. https://doi.org/10.1007/s10311-020-01171-x 
[15] A. E. Shalan, W. Sharmoukh, A. N. Elshazly, M. M. Elnagar, S. A. Al Kiey, M. M. Rashad, and N. K. Allam, Dopant-Free Hole-Transporting Polymers for Efficient, Stable, and HysteresisLess Perovskite Solar Cells, Sustainable Materials and Technologies, 26(2020), e00226. https://doi.org/10.1016/j.susmat.2020.e00226

[16] T. Dai, Q. Cao, L. Yang, M. H. Aldamasy, M. Li, Q. Liang, H. Lu, Y. Dong, and Y. Yang, Strategies for High-Performance Large-Area Perovskite Sola Cells toward Commercialization, Crystals,11(3)(2021)295. https://doi.org/10.3390/cryst11030295

[17] A. Bonadio, C. A. Escanhoela, Jr, F. P. Sabino, G. Sombrio, V. G. de Paula, F. F. Ferreira, A. Janotti, G. M. Dalpian , and J. A. Souza , Entropy-driven stabilization of the cubic phase of $\mathrm{MaPbI}_{3}$ at room temperature, J. Mater. Chem. A, 9(2021) 10891099.

https://doi.org/10.1039/d0ta10492b

[18] M. M. Salah, M. Abouelatta, A. Shaker, K. M. Hassan, and A. Saeed, A Comprehensive Simulation Study of Hybrid Halide Perovskite Solar Cell with Copper Oxide as HTM, Semiconductor Science and Technology, 34 (2019) 115009.

https://doi.org/10.1088/1361-6641/ab22e1

[19] Z. Shi, and A. H. Jayatissa, Perovskites-Based Solar Cells: A Review of Recent Progress, Materials and Processing Methods, Materials, 11 (2018) 729. https://doi.org/10.3390/ma11050729

[20] M. Mehrabian, and S. Dalir, $11.73 \%$ Efficient Perovskite Heterojunction Solar Cell Simulated by SILVACO ATLAS Software, Optik International Journal for Light and Electron Optics , 139(2017) 44-47.

https://doi.org/10.1016/j.ijleo.2017.03.077

[21] L. Lin, T. W. Jones, T. C.Yang, N. W. Duffy, J. Li, L. Zhao, B. Chi, X. Wang, and G. J. Wilson, Adv. Funct. Mater., 31(2021)2008300. https://doi.org/10.1002/adfm.202008300

[22] H. Du, W. Wang, and J. Zhu, Device simulation of lead-free $\mathrm{CH}_{3} \mathrm{NH}_{3} \mathrm{SnI}_{3}$ perovskite solar cells with high efficiency, Chin. Phys. B, 25(2016). 108802. https://doi.org/10.1088/16741056/25/10/108802

[23] S. D. Sung, D. P. Ojha, J. S. You, J. Lee, J. Kim, and W. I. Lee, $50 \mathrm{~nm}$ sized spherical $\mathrm{TiO}_{2}$ nanocrystals for highly efficient mesoscopic perovskite solar cells, Nanoscale, 7(2015) 88988906. https://doi.org/10.1039/C5NR01364J

[24] A. E. Shalan, S. Kazim, and S. Ahmad, Lead-Free Perovskites: Metals Substitution towards
Environmentally Benign Solar Cell Fabrication, ChemSusChem, 12 (2019) 4116-4139. https://doi.org/10.1002/cssc.201901296

[25] A. A. Kanoun, M. B. Kanoun, A. E. Merad, and S. Goumri-Said, Toward development of highperformance perovskite solar cells based on $\mathrm{CH}_{3} \mathrm{NH}_{3} \mathrm{GeI}_{3}$ using computational approach, Solar Energy, 182(2019) 237-244. https://doi.org/10.1016/j.solener.2019.02.041

[26] F. BAIG, Y. H. KHATTAK, B. MARI', S. BEG, A. AHMED, and K. KHAN, Efficiency Enhancement of $\mathrm{CH}_{3} \mathrm{NH}_{3} \mathrm{SnI}_{3}$ Solar Cells by Device Modelling, Journal of ELECTRONIC MATERIALS, 47 (2018)5275-5282. https://doi.org/10.1007/s11664-018-6406-3

[27] J. Cao, and F. Yan, Recent progress in tin-based perovskite solar cells, Energy Environ. Sci., 14 (2021)1286-1325. https://doi.org/10.1039/d0ee04007i

[28] A. E. Shalan, M. K. A. Mohammed, and N. Govindan, Graphene assisted crystallization and charge extraction for efficient and stable perovskite solar cells free of a hole-transport layer, RSC Adv., 11 (2021) 4417- 4424. https://doi.org/10.1039/D0RA09225H

[29] Y. Wu, D. Wang, J. Liu, and H. Cai, Review of Interface Passivation of Perovskite Layer, Nanomaterials ,11 (3)(2021) 775. https://doi.org/10.3390/nano11030775

[30] T. Minemoto, and M. Murata, Theoretical analysis on effect of band offsets in perovskite solar cells, Solar Energy Materials \& Solar Cells, 133 (2015) 8-14. https://doi.org/10.1016/j.solmat.2014.10.036

[31] A. Sahu, and A. Dixit, Inverted structure perovskite solar cells: A theoretical study, Current Applied Physics, 18 (2018) 1583-1591. https://doi.org/10.1016/j.cap.2018.10.008

[32] T. Wang, J. Chen, G. Wu and M. Li, Optimal design of efficient hole transporting layer free planar perovskite solar cell, Science China Materials, 59 (2016) 703-709.

https://doi.org/10.1007/s40843-016-5108-4

[33] M. I. Hossain, F. H. Alharbi, and N. Tabet, Copper oxide as inorganic hole transport material for lead halide perovskite based solar cells, Solar Energy, 120 (2015) 370-380. https://doi.org/10.1016/j.solener.2015.07.00

[34] R. Pandey, A. P. Saini, and R. Chaujar, Numerical simulations: Toward the design of $18.6 \%$ efficient and stable perovskite solar cell using reduced cerium oxide based ETL, Vacuum ,159 (2019) 173-181. 
https://doi.org/10.1016/j.vacuum.2018.10.03

[35] Y. Wang, Z. Xia, Y. Liu, and H. Zhou, Simulation of perovskite solar cells with inorganic hole transporting Materials, IEEE 42 ${ }^{\text {nd }}$ Photovoltaic Specialist Conference (PVSC), (2015). http://doi.org/10.1109/PVSC.2015.7355717

[36] Z. Song, S. C. Watthage, A. B. Phillips, and M. J. Heben, Pathways toward high-performance perovskite solar cells: review of recent advances in organo-metal halide perovskites for photovoltaic applications, Journal of Photonics for Energy, 6 (2016) 022001. https://doi.org/10.1117/1.JPE.6.022001

[37] Z. Li, T. R. Klein, D. H. Kim, M. Yang, J. J. Berry, M. F. A. M. van Hest, and K. Zhu, Scalable fabrication of perovskite solar cells, Materials, 3 (2018) 18017.

https://doi.org/10.1038/natrevmats.2018.17

[38] M. Giannouli, Current Status of Emerging PV Technologies: A Comparative Study of DyeSensitized, Organic, and Perovskite Solar Cells, International Journal of Photo-energy, (2021) 6692858 .

https://doi.org/10.1155/2021/6692858

[39] F. Sadegh, S. Akin, M. Moghadam, R. Keshavarzi, V. Mirkhani, M. A. Ruiz-Preciado, E. Akman, H. Zhang, M. Amini, S.Tangestaninejad, I. M. poorBaltork, M. Graetzel, A. Hagfeldt, and W. Tress, Copolymer-Templated Nickel Oxide for HighEfficiency Mesoscopic Perovskite Solar Cells in Inverted Architecture, Adv. Funct. Mater. , 31(2021)2102237. https://doi.org/10.1002/adfm.202102237

[40] Z. Zhu,, X. Zheng, Y. Bai, T. Zhang, Z. Wang, S. Xiao, and S. Yang, Mesoporous $\mathrm{SnO}_{2}$ single crystals as an effective electron collector for perovskite solar cells, Phys. Chem. Chem. Phys., 7 (2015) 18265-18268.

https://doi.org/10.1039/C5CP01534K

[41] P. Lopez-Varo , L. Bertoluzzi , J. Bisquert , M. Alexe, M. Coll , J. Huang, J. A. Jimenez-Tejada, T. Kirchartz, R. Nechache, F. Rosei, and Y.Yuan, Physical aspects of ferroelectric semiconductors for photovoltaic solar energy conversion, Physics Reports , 653 (2016) 1-40.

https://doi.org/10.1016/j.physrep.2016.07.006

[42] D. Rossi, M. Auf der Maur, A. Pecchia, and A. D. Carlo, Simulations of 3-dimensional ferroelectric domains in perovskite solar cells based on $\mathrm{MAPbI}_{3}$, International Conference on Numerical Simulation of Optoelectronic Devices (NUSOD) IEEE
[43] T. S. Sherkar, and L. J. Anton Koster, Can ferroelectric polarization explain the high performance of hybrid halide perovskite solar cells, Phys. Chem. Chem. Phys. , 18(2016)331338 . https://doi.org/10.1039/C5CP07117H

[44] A. Pecchia, D. Gentilini, D. Rossi, M. Auf der Maur, and A. D. Carlo, The Role of Ferroelectric Nanodomains in the Transport Properties of Perovskite Solar Cells, Nano Lett., 16 (2016) 988-992.

https://doi.org/10.1021/acs.nanolett.5b03957

[45] I. Yahyaoui, Advances in Renewable Energies and Power Technologies volume 1: Solar and Wind Energies, Jonathan Simpson, Spain (2018).

[46] P. Würfel, Physics of Solar Cells, WILEY-VCH Verlag GmbH \& Co. KGaA, Weinheim, (2005). https://doi.org/10.1002/9783527618545

[47] N. S. Kumar, and K. C. B. Naidu, A review on perovskite solar cells (PSCs), materials and applications, Journal of Materiomics ,5 (2021) 940-956. https://doi.org/10.1016/j.jmat.2021.04.002

[48] B.M. Soucase, I.G. Pradas, and K.R. Adhikari, Numerical simulations on perovskite photovoltaic devices, In: Pan, L., Zhu, G. (eds.), Perovskite materials - synthesis, characterization, properties, and applications, InTech. , London (2016) 445486.

http://dx.doi.org/10.5772/61751

[49] G. S. Spagnolo, F. Leccese, and M. Leccisi, LED as Transmitter and Receiver of Light: A Simple Tool to Demonstration Photoelectric Effect, Crystals 9 (2019) 531. https://doi.org/10.3390/cryst9100531

[51] Y. Wang, C. Duan, P. Lv, Z. Ku, J. Lu , F. Huang, and Y. Cheng, Printing strategies for scaling-up perovskite solar cells, Natl Sci Rev, 0(2021) nwab075. https://doi.org/10.1093/nsr/nwab075

[52] T. Soto-Montero, W. Soltanpoor, and M. MoralesMasis, Pressing challenges of halide perovskite thin film growth, APL Mater. , 8 (2020) 110903. https://doi.org/10.1063/5.0027573

[53] L. Qiu, L. K. Ono , and Y. Qi , Advances and challenges to the commercialization of organicinorganic halide perovskite solar cell technology, Materials Today Energy, 7 (2018) 169-189. https://doi.org/10.1016/j.mtener.2017.09.008

[54] Q. Tai, X. Guo, G. Tang, P. You, T. Ng, D. Shen, J. Cao, C.Liu, N. Wang, Y. Zhu, C. Lee, F. Yan, Antioxidant Grain Passivation for Air-Stable Tin- 
Based Perovskite Solar Cells, Angew. Chem. Int. Ed., 58 (2019) 806 -810. https://doi.org/10.1002/anie.201811539

[55] J. Wang, J. Dong, F. Lu, C. Sun, Q. Zhang, and N. Wang, Two-Dimensional Lead-Free Halide Perovskite Materials and Devices, Journal of Materials Chemistry A, 7 (2019)23563-23576. https://doi.org/10.1039/C9TA06455A

[56] D. Li, D. Zhang, K. Lim, Y. Hu, Y. Rong, A. Mei, N. Park, and H. Han , A Review on Scaling Up Perovskite Solar Cells, Adv. Funct. Mater. , 31 (2021)2008621. https://doi.org/10.1002/adfm.202008621

[57] B. Chen, X. Zheng, M. Yang, Y. Zhou, S. Kundu, J. Shi, K. Zhu, and S. Priya, Interface band structure engineering by ferroelectric polarization in perovskite solar cells, Nano Energy, 13(2015) 582-591.

https://doi.org/10.1016/j.nanoen.2015.03.037

[58] M. Wang, H. Feng, C. Qian, J. He, J. Feng, Y. Cao, K. Yang, Z. Deng, Z. Yang, X. Yao, J. Zhou, S. Liu, and X. C. Zeng, $\mathrm{PbTiO}_{3}$ as Electron-Selective Layer for High-Efficiency Perovskite Solar Cells: Enhanced Electron Extraction via Tunable Ferroelectric Polarization, Adv. Funct. Mater. , 29 (2019) 1806427.

https://doi.org/10.1002/adfm.201806427

[59] S. Agarwal, and P. R. Nair, Performance optimization for perovskite based solar cells, IEEE 40th Photovoltaic Specialist Conference (PVSC), (2014)1515-1518. https://doi.org/10.1109/PVSC.2014.6925202

[60] E. Velilla, J. B. Cano, K. Jimenez, J. Valencia, D. Ramirez, and F. Jaramillo, Numerical Analysis to Determine Reliable One-Diode Model Parameters for Perovskite Solar Cells, Energies, 11 (8) (2018)1963.

https://doi.org/10.3390/en11081963

[61] I. Moeini, M. Ahmadpour, A. Mosavi, N. Alharbi, and N. E. Gorji, Modeling the time-dependent characteristics of perovskite solar cells, Solar Energy ， $170 \quad$ (2018) 969-973. https://doi.org/10.1016/j.solener.2018.05.082

[62] M. Gagandeep, R. Singh, V. Kumar, F. Singh, A. Chand, Theoretical Study of Perovskite Material for Solar Cell Application, AIP Conference Proceedings, (2018) 030018. https://doi.org/10.1063/1.5051274

[63] M. Jamadi, F. Merrikh-Bayat , and M. Bigdeli , Very accurate parameter estimation of single- and double-diode solar cell models using a modified artificial bee colony algorithm, International Journal of Energy and Environmental
Engineering, 7(2016)13-25. http://doi.org/10.1007/s40095-015-0198-5

[64] S. Pitchaiya , M. Natarajan , A. Santhanam , V. Asokan, A. Yuvapragasam, V. M. Ramakrishnan , S. E. Palanisamy, S. Sundaram, and D. Velauthapillai, A review on the classification of organic/ Inorganic/carbonaceous hole transporting materials for perovskite solar cell application, Arabian Journal of Chemistry ,13 (2020) 2526-2557.

https://doi.org/10.1016/j.arabjc.2018.06.006

[65] L. Pedesseau, M. Kepenekian, D. Sapori, Y. Huang, A. Rolland, A. Beck, C. Cornet, O. Durand, S. Wang, C. Katan, and J. Even, Dielectric properties of hybrid perovskites and Drift- diffusion modeling of perovskite cells, Physics, Simulation, and Photonic Engineering of Photovoltaic Devices V, 9743 (2016) 97430N. https://doi.org/10.1117/12.2214007

[66] D. K. Jarwal, A. K. Mishra, A. Kumar, S. Ratan , A. P. Singh , C. Kumar, B. Mukherjee, and S. Jit , Fabrication and TCAD simulation of $\mathrm{TiO} 2$ nano rods electron transport layer based perovskite solar cells, Super lattices and Microstructures, 140 (2020) 106463. https://doi.org/10.1016/j.spmi.2020.106463

[67] D. Rossi, A. Pecchia, M. Auf der Maur, T. Leonhard, H. Röhm, M. J. Hoffmann, A. Colsmann, and A. D. Carlo, On the importance of ferroelectric domains for the performance of perovskite solar cells, Nano Energy, 48 (2018) 2026. https://doi.org/10.1016/j.nanoen.2018.02.049

[68] H. Du, W. Wang, and Y. Gu, Simulation design of P-I-N-type all-perovskite solar cells with high efficiency, Chin. Phys. B, 26 (2) (2017) 028803. https://doi.org/10.1088/16741056/26/2/028803

[69] S. Z. Haider, H. Anwar, and M. Wang , A comprehensive device modelling of perovskite solar cell with inorganic copper iodide as hole transport material, Semiconductor Science and Technology, 33(3) (2018) 035001. https://doi.org/10.1088/1361-6641/aaa596

[70] S. Bansal, and P. Aryal, Evaluation of New Materials for Electron and Hole Transport Layers in Perovskite-Based Solar Cells Through SCAPS1D Simulations, IEEE 43rd Photovoltaic Specialists Conference (PVSC), (2016) 07470750 .

\section{http://doi.org/10.1109/PVSC.2016.7749702}

[71] N. Wu, Y. Wu, D. Walter, H. Shen, T. Duong, D. Grant, C. Barugkin, X. Fu, J. Peng, T. White, K. Catchpole, and K. Weber, Identifying the Cause of Voltage and Fill Factor Losses in Perovskite Solar 
Cells by Using Luminescence Measurements, Energy Technology, 5 (2017) 1827 - 1835.

https://doi.org/10.1002/ente.201700374

[72] S. Bishnoi, and S. K. Pandey, Device performance analysis for lead-free perovskite solar cell optimization, IET Optoelectronics, 12 (4) (2018) 185-190.

https://doi.org/10.1049/iet-opt.2017.0135

[73] M. M. Salah, K. M. Hassan, M. Abouelatta, and A. Shaker, A comparative study of different ETMs in perovskite solar cell with in-organic copper iodide as HTM, Optik International Journal for Light and Electron Optics , 178(2019) 958-963. https://doi.org/10.1016/j.ijleo.2018.10.052

[74] N. Lakhdar, and A. Hima, Electron transport material effect on performance of perovskite solar cells based on $\mathrm{CH}_{3} \mathrm{NH}_{3} \mathrm{GeI}_{3}$, Optical Materials, 99 (2020) 109517.

https://doi.org/10.1016/j.optmat.2019.109517 